\title{
Mecanismos de Governança Corporativa e - Desempenho Econômico-Financeiro e de Mercado de Empresas Brasileiras listadas no Nível 1, Nível 2 e Novo Mercado
}

\section{Corporate Governance Mechanisms and the Economic-Financial and Market Performance of Brazilian Companies listed on Level 1, Level 2 and New Market}

\author{
LARISSA DEGENHART (D) \\ LUANA DA SILVA SOARES \\ GLEICA SAVEGNAGO CASARIN \\ LUIZ HENRIQUE FIGUEIRA MARQUEZAN \\ CRISTIANO SAUSEN SOARES

\section{RESUMO}

Esta pesquisa objetivou analisar a relação entre os mecanismos de governança corporativa e o desempenho de empresas brasileiras. Estudo descritivo, documental e quantitativo. A população compreendeu empresas listadas nos níveis de governança corporativa da B3. A amostra constituiu de 19 empresas do Nível 1, 14 do Nível 2 e 104 do Novo Mercado, totalizando 137 empresas. O período de análise compreendeu 2014 a 2018 e utilizou-se a regressão múltipla. Para as empresas do Nível 1, os resultados revelaram relação positiva do comitê de auditoria com ROA. A expertise do conselho relacionou-se positivamente com o ROA (Nível 2). Em contrapartida, nenhuma das variáveis de governança influenciaram o desempenho de mercado. Os resultados das empresas do Novo Mercado indicaram uma relação negativa entre a independência do conselho e o ROA. Relação positiva entre auditoria Big Four, tamanho e expertise do conselho e o 
ROA, e relação positiva entre o comitê de auditoria e a expertise do conselho e o $Q$ de Tobin. Estes resultados confirmam as premissas da Teoria da Agência, de que os mecanismos tendem a minimizar os conflitos de agência e maximizar o valor das partes interessadas. Conclui-se que os mecanismos devem ser considerados nas empresas para aprimorar as práticas de governança, pois auxiliam na melhora do desempenho.

Palavras-chave: Governança Corporativa; Conselho de Administração; Desempenho Empresarial.

\begin{abstract}
This research aimed to analyze the relationship between corporate governance mechanisms and the performance of Brazilian companies. Descriptive, documentary and quantitative study. The population comprised companies listed in the corporate governance levels of B3. The sample consisted of 19 companies from Level 1, 14 from Level 2 and 104 from the Novo Mercado, totaling 137 companies. The analysis period ranged from 2014 to 2018 and multiple regression was used. For Level 1 companies, the results revealed a positive relationship between the audit committee and ROA. The board's expertise was positively related to ROA (Level 2). In contrast, none of the governance variables influenced market performance. The results of the Novo Mercado companies indicated a negative relationship between board independence and ROA. Positive relationship between Big Four audit, size and expertise of the board and ROA, and positive relationship between the audit committee and the board's expertise and Tobin's Q. These results confirm the premises of the Agency Theory, that mechanisms tend to minimize agency conflicts and maximize the value of stakeholders. It is concluded that the mechanisms should be considered in companies to improve governance practices, as they help to improve performance. Keywords: Corporate governance; Administrative Council; Business Performance.
\end{abstract}

\title{
1. INTRODUÇÃO
}

O conflito de interesses entre os proprietários e administradores "especialmente em relação às suas prováveis consequências para o desempenho das firmas, repercutiu no surgimento da Teoria 
da Agência" (CAIXE; KRAUTER, 2013, p. 142). Esta teoria aborda que o proprietário das empresas, considerado o principal, possui como função monitorar as atividades desenvolvidas pelo gestor, denominado de agente, com vistas a criar incentivos contratuais para ele e de certas práticas do administrador que visam o benefício próprio e não o atendimento dos interesses dos acionistas (JENSEN; MECKLING, 1976).

Conforme o Instituto Brasileiro de Governança Corporativa (IBGC, 2004), a governança corporativa visa superar o conflito de agência presente a partir da separação entre propriedade e controle (gestão empresarial). Nesse contexto, o principal refere-se ao titular da empresa e delega ao agente o poder de decisão sobre sua entidade. A partir do momento em que o agente toma decisões em nome do principal, surgem os conflitos de agência, pois os interesses do agente nem sempre estão alinhados com os do principal. Assim, faz-se necessário as empresas criarem mecanismos eficientes, com vistas a garantir que o comportamento dos agentes esteja alinhado com os interesses dos sócios, proprietários e acionistas (IBGC, 2004).

Nesse sentido, o conselho de administração das empresas "possui uma função importante, que é supervisionar a administração em nome dos acionistas" (COSTA; MARTINS, 2019, p. 404). Além disso, "desempenha um papel importante nas organizações, sendo responsável por tomar decisões estratégicas essenciais para o desenvolvimento das empresas" (COSTA; MARTINS, 2019, p. 404). Para Uadiale (2010), os teóricos da Teoria da Agência argumentam que, para proteger os interesses dos acionistas, o conselho de administração necessita desenvolver uma função eficaz de supervisão, pois os conflitos de interesses existentes nas empresas podem "representar uma ameaça para a sociedade e realização de objetivos organizacionais (COSTA; MARTINS, 2019, p. 404).

Para tanto, "a questão da estrutura do Conselho de Administração como mecanismo de governança corporativa recebeu considerável atenção nos últimos anos de acadêmicos, participantes do mercado e reguladores". Deste modo, entender se os mecanismos de governança corporativa influenciam o desempenho e o valor das empresas é uma questão relevante (UADIALE, 2010, p. 155). Diversos preceitos de governança corporativa foram discutidos na 
literatura com vistas a "alinhar interesses de acionistas, gerência, força de trabalho e outras partes interessadas" (AMARAL-BAPTISTA; KLOTZLE; MELO, 2011, p. 25). Assim, investidores e outras partes interessadas nas empresas, começaram a perceber a importância de boas práticas de governança corporativa, pois estas podem proteger seus interesses (EHIKIOYA, 2009). Deste modo, os mecanismos de governança corporativa podem atuar com vistas a evitar possíveis conflitos de interesses, proteger os acionistas, e apresentar reflexos no desempenho das empresas. Esta perspectiva é fundamentada na Teoria da Agência que aborda o alinhamento de interesses de proprietários e gerentes (JENSEN; MECKLING, 1976).

Estudos internacionais foram desenvolvidos com vistas a identificar as relações existentes entre os mecanismos de governança corporativa e o desempenho empresarial (ADAMS; FERREIRA, 2009; EHIKIOVA, 2009; UADIALE, 2010; DARMADI, 2011; UJUNWA, 2012; MOSCU, 2013; AKPAN; AMRAN, 2014; GAUR; BATHULA; SINGH, 2015; WAHBA, 2015). No entanto, a influência de mecanismos de monitoramento das decisões dos executivos (independência do conselho de administração, dualidade do diretor, auditoria Big Four, comitê de auditoria, tamanho, expertise e gênero do conselho) no desempenho das empresas brasileiras ainda não consolidou evidências suficientes para se constituir uma corrente teórica sobre estas temáticas (ANDRADE et al., 2009). Costa e Martins (2019, p. 4) abordam que "não há consenso claro sobre esse assunto", o que estimula o desenvolvimento da presente pesquisa e se constitui como lacuna teórica identificada na literatura.

No Brasil, pesquisas que objetivaram analisar os mecanismos de governança corporativa e o desempenho empresarial são escassos (ANDRADE et al., 2009; AMARAL-BAPTISTA; KLOTZE; MELO, 2011; DANI et al., 2017; COSTA; MARTINS, 2019). Para tanto, esta pesquisa propôs investigar com maior profundidade quais os mecanismos de governança corporativa impactam o desempenho de empresas brasileiras, com o intuito de promover uma maior compreensão acerca de quais variáveis são as mais representativas desta relação.

Considerando a importância das temáticas abordadas, busca-se a partir do desenvolvimento deste estudo responder a seguinte questão de pesquisa: Qual a relação entre os mecanismos de go- 
vernança corporativa e o desempenho empresarial de empresas brasileiras? Como objetivo, busca-se analisar a relação entre os mecanismos de governança corporativa e o desempenho empresarial de empresas brasileiras.

Justifica-se o desenvolvimento desta pesquisa, pois Ehikiova (2009) destaca que um sistema de governança bem definido contribui para atrair investimentos, captar recursos, elevar o desempenho da empresa, além de proteger a organização de vulnerabilidades futuras. Contudo, conforme Andrade et al. (2009) diversos estudos têm buscado explicar a relação dos diferentes mecanismos de governança corporativa sobre o desempenho econômico-financeiro e de mercado, mas por ser uma temática que permite enfoques distintos, ainda não há uma consistência teórica dos resultados, o que estimula e justifica o desenvolvimento desta pesquisa. Justifica-se ainda a realização desta pesquisa, pois de acordo com Hsu e Petchsakulwong (2010), a temática da governança corporativa e desempenho é relevante para os investidores, visto que os mecanismos de governança corporativa, mais precisamente o conselho de administração, possui um importante papel na tomada de decisões sobre as políticas e estratégias adotadas por uma organização.

A presente pesquisa se diferencia de outras já realizadas sobre esta temática, por analisar os impactos dos mecanismos de governança corporativa no desempenho de empresas brasileiras pertencentes a três níveis diferenciados de governança corporativa (Nível 1, Nível 2 e Novo Mercado), com vistas a identificar quais mecanismos de governança corporativa possibilitam aumentar o desempenho econômico-financeiro e de mercado destas empresas, aspectos estes pouco explorados sob o prisma dos três níveis de governança da B3. Além disso, os resultados auxiliarão as empresas brasileiras a identificar quais mecanismos de governança corporativa devem fortalecer no seu conselho de administração para obter melhor desempenho empresarial.

Optou-se por analisar empresas brasileiras, pois o Brasil passou por diversas "mudanças estruturais significativas em suas práticas de governança corporativa, resultantes de privatizações maciças, investimento institucional estrangeiro, crescimento econômico, reformas na estrutura legal e regulamentação dos mercados financei- 
ros locais" (AMARAL-BAPTISTA; KLOTZLE; MELO, 2011, p. 25). Além disso, entre as economias consideradas emergentes, "o Brasil foi um dos primeiros a publicar diretrizes de governança corporativa e códigos de boas práticas" (AMARAL-BAPTISTA; KLOTZLE; MELO, 2011, p. 25).

Esta pesquisa contribui para a literatura, pois visa ampliar os resultados da relação entre os mecanismos de governança corporativa e o desempenho empresarial no cenário brasileiro. No que tange a literatura sobre governança corporativa, este estudo contribui pelo fato de analisar uma economia em desenvolvimento que apresenta diferentes ambientes econômicos, culturais e jurídicos. Como implicações práticas, destaca-se a visão de Ehikiova (2009), pois os autores abordam que os bons padrões de governança corporativa podem ser considerados imperativos para todas as empresas e devem ser incentivados com vistas a atrair o interesse dos investidores e demais partes interessadas. Os resultados desta pesquisa fornecem informações úteis para os formuladores de políticas, acadêmicos, partes interessadas (EHIKIOVA, 2009) e profissionais sobre a importância das práticas de governança corporativa (UJUNWA, 2012).

\section{REVISÃo DE LITERATURA}

\subsection{Mecanismos de Governança Corporativa}

A governança corporativa "lida com as maneiras pelas quais os fornecedores de financiamento das empresas se asseguram de obter um retorno sobre o investimento" (SHLEIFER; VISHNY, 1997, p. 737). Para tanto, a criação de um ambiente de proteção legal aos investidores é considerada, na governança corporativa, o principal motivo para que as práticas de governança listadas nos códigos sejam colocadas em ação nas empresas (ANDRADE et al., 2009). Nesse sentido, a governança corporativa objetiva assegurar que os membros interessados no bem-estar da empresa tomam decisões com vistas a proteger os interesses dos acionistas, pois a boa governança corporativa centra-se nos princípios de prestação de contas, transparência, justiça e responsabilidade na gestão das companhias (EHIKIOYA, 2009). Além disso, é importante no fornecimento de garantias e mecanismos que possam minimizar os conflitos de in- 
teresses e os desequilíbrios informacionais entre os investidores e a gestão da empresa (COSTA; MARTINS, 2019).

Assim, a instituição de mecanismos de governança corporativa nas empresas é uma tentativa de garantir a separação entre propriedade e controle, o que geralmente resulta em problemas entre o agente e o principal (JENSEN; MECKLING, 1976). Portanto, os mecanismos de governança corporativa têm a função de compor o sistema interno de controle de gestão, objetivando direcionar a conduta dos administradores para o cumprimento das metas estipuladas pelos acionistas (IBGC, 2009). De acordo com a Comissão de Valores Mobiliários (CVM, 2002), governança corporativa refere-se ao conjunto de práticas que objetivam otimizar o desempenho empresarial ao proteger as partes interessadas e facilitando o acesso a recursos.

Uma boa governança corporativa passa a proteger as empresas de vulnerabilidades e problemas financeiros futuros (EHIKIOYA, 2009). Denota-se a importância de as empresas terem mecanismos de governança corporativa desenvolvidos, com vistas a assegurar que os interesses das partes interessadas sejam protegidos (MALACRIDA; YAMAMOTO, 2006) e que estes mecanismos visam também promover o desempenho das empresas.

Conforme a Teoria da Agência, a separação entre propriedade e controle provoca assimetria de informação entre acionistas e gerência das empresas. Para evitar práticas oportunistas da gerência, a delegação de responsabilidades por parte dos proprietários exige a presença de mecanismos para a alinhar os interesses dos diretores e agentes, com vistas a garantir a maximização da riqueza dos acionistas (AMARAL-BAPTISTA; KLOTZLE; MELO, 2011). Nesse sentido, as estruturas de governança corporativa lidam com a estrutura acionária das empresas e a composição do conselho de administração, como por exemplo a proporção de conselheiros independentes, a expertise, a habilidade, o tamanho do conselho, a separação da responsabilidade do $\mathrm{CEO}$, da responsabilidade do presidente (dualidade do CEO), entre outras questões relacionadas às empresas (EHIKIOYA, 2009).

Quando estes mecanismos de governança corporativa são bem definidos e funcionais, ajudam a atrair investimentos e fortalecer as bases para o desempenho empresarial (EHIKIOYA, 2009; CALDAS; 
TAMBOSI FILHO; VIEIRA, 2014). Portanto, a governança corporativa possui mecanismos que, segundo Silveira (2006), objetivam garantir e aumentar o retorno sobre os investimentos dos investidores. Dessa forma, há mecanismos de proteção aos acionistas de forma a alinhar os interesses entre todas as partes interessadas na empresa e entre acionistas e gestores, e, consequentemente para melhorar o desempenho empresarial.

\subsection{Desempenho Empresarial}

A Contabilidade é considerada uma importante área provedora de informações para a avaliação do desempenho empresarial (GASPARETTO, 2004). A avaliação do desempenho empresarial é essencial para as organizações manterem o equilíbrio da competitividade. De acordo com Gasparetto (2004, p. 110), “com a frequência com que ocorrem mudanças no ambiente empresarial, constantemente os tomadores de decisão veem-se diante de novas demandas também em termos de informações", logo se faz necessária a análise do desempenho pois o objetivo de toda a empresa é melhorar o seu desempenho (CHEN; CHEN; PENG, 2008).

A partir da utilização de diversos indicadores de desempenho, as empresas podem avaliar a eficiência e a eficácia de suas atividades com os objetivos estratégicos (CHEN; CHEN; PENG, 2008). Para tanto, a análise das demonstrações contábeis, conforme Assaf Neto (2012), tem o intuito de relatar a situação econômico-financeira da empresa, as causas que determinaram as variações do patrimônio, a situação atual e as tendências futuras, sendo este processo desenvolvido com base nos mais diversos indicadores contábeis.

A análise do desempenho empresarial a partir da utilização de índices é imprescindível para as empresas evidenciarem sua situação econômica, capacidade de financiamentos, investimentos, pagamentos. Além disso, é essencial para a tomada de decisões (REZENDE et al., 2010). Deste modo, a análise dos indicadores financeiros é relevante, "na medida em que a compreensão do passado é o primeiro passo para o entendimento do futuro e, inclusive, pode permitir a comparação do nível de risco e retorno em determinado horizonte temporal, de forma a auxiliar os tomadores de decisão" (SILVA; CORDEIRO FILHO, 2015, p. 19). “Os indicadores de desempenho 
empresarial são elaborados com o propósito de fornecer suporte necessário aos tomadores de decisão e a sobrevivência da organização" (DANI et al., 2017, p. 35). Assim, o desempenho empresarial pode ser analisado tanto em relação ao desempenho econômico-financeiro das empresas, quanto ao desempenho de mercado.

De acordo com Assaf Neto (2012), os indicadores referentes ao desempenho de mercado objetivam avaliar o desempenho da empresa sobre suas ações no mercado financeiro e pode ser analisado por meio de diversos índices, como por exemplo, o indicador $Q$ de Tobin. O desempenho econômico-financeiro visa mensurar a situação da empresa em relação ao seu patrimônio. Dentre os índices, destaca-se o Retorno sobre os Ativos (ROA), Retorno sobre os Investimentos (ROI) e o Retorno sobre o Patrimônio Líquido (ROE). Conforme Uadiale (2010, p. 156) "ao longo dos anos, diferentes variáveis foram usadas para medir o desempenho corporativo". Nesta pesquisa, o desempenho econômico-financeiro foi mensurado por meio do ROA e ROE e o desempenho de mercado a partir do $Q$ de Tobin.

Silva e Cordeiro Filho (2015) abordam que o indicador ROA mostra quanto a empresa obteve de lucro líquido em relação ao ativo e é considerado como uma medida do potencial de geração de lucro da empresa. O ROE é uma medida assim como o ROA de importância para os analistas financeiros, pois demonstra a rentabilidade dos recursos dos acionistas, no que tange aos recursos totais da empresa (FERNANDES, DIAS; CUNHA, 2010). Em relação ao $Q$ de Tobin, Famá e Barros (2000) o definem como sendo a relação entre o valor de mercado de uma organização e o seu valor de reposição dos seus ativos considerados físicos e revela oportunidades para novos investimentos rentáveis para as empresas (FAMÁ; BARROS, 2000).

\subsection{Desenvolvimento das Hipóteses e Modelo Teórico de Análise}

A governança corporativa "representa uma ferramenta capaz de alavancar o desempenho econômico-financeiro das empresas, além de apresentar-se como uma forma de assegurar o retorno sobre investimentos dos fornecedores de recursos financeiros". Nesse sentido, "boas práticas de governança corporativa tendem a melhorar o desempenho econômico, aumentar o retorno sobre o investimento, bem como aumentar o valor da empresa" (FERNANDES, DIAS; 
CUNHA, 2010, p. 22).

O conselho de administração é visto como um órgão que tem a responsabilidade de decidir em nome dos proprietários e desempenha diversas atividades (monitoramento das decisões e a supervisão da gestão, contratação, demissão e definição da remuneração dos executivos. Essas "atribuições, assumidas pelo conselho de administração, são fatores importantes que podem contribuir para explicar uma parte tanto do desempenho quanto do valor de mercado das empresas" (ANDRADE et al., 2009, p. 6).

O conselho de administração é um elemento fundamental na governança corporativa das empresas, pois segundo Silveira (2002), é o principal mecanismo interno para a diminuição dos conflitos de agência. Os conselhos de administração são compostos por membros internos e externos (independentes) (HSU; PETCHSAKULWONG, 2010) e de acordo com Silveira (2006) possuem a responsabilidade de controlar a alta gestão, ratificar as decisões relevantes tomadas e monitorar a gerência da empresa. Nesse sentido, um dos principais mecanismos de governança corporativa, apresentado pela literatura é o conselho de administração (SILVEIRA, 2006). Para tanto, uma das características do conselho de administração é a independência, que "refere-se ao número de conselheiros não executivos independentes no conselho em relação ao número total de conselheiros" (UADIALE, 2010, p. 157).

$\mathrm{O}$ "efeito de membros não executivos (independentes) do conselho de administração é amplamente analisado na literatura de governança corporativa" (WAHBA, 2015, p. 22-23). Conforme a Teoria da Agência, conselhos que possuem uma proporção maior de conselheiros independentes provavelmente serão monitores, mas eficazes das práticas realizadas nas empresas (WAHBA, 2015). Isto ocorre, pois, os conselheiros independentes são capazes de trabalhar livremente e não estão sujeitos ao controle dos principais acionistas e administradores. Deste modo, é provável que questionem e monitorem a empresa para evitar fraudes (HSU; PETCHSAKULWONG, 2010). Além disso, “existe uma presunção aparente de que os conselhos com diretores externos significativos tomarão decisões diferentes e talvez melhores do que os conselhos dominados por 
especialistas" (UADIALE, 2010, p. 157).

Os impactos da independência do conselho de administração no desempenho empresarial foram analisados, contudo, os resultados podem ser considerados conflitantes e inconclusivos (WAHBA, 2015). Evidências encontradas na literatura revelaram que a independência do conselho se relaciona positivamente com o ROE (WAHBA, 2015), negativamente com o ROA (ADAMS; FERREIRA, 2009; DANI et al., 2017) e $Q$ de Tobin (ADAMS; FERREIRA, 2009; WAHBA, 2015). Os achados também indicaram que não há uma relação significativa entre a independência e o desempenho empresarial (ANDRADE et al., 2009; UADIALE, 2010; AKPAN; AMRAN, 2014). Deste modo, propõem-se a seguinte hipótese de pesquisa: $\mathrm{H} 1$ : a maior proporção de membros independentes do conselho de administração aumenta o desempenho empresarial.

A função dos conselhos e os papéis dos CEOs é executada conforme o poder exercido dentro da organização (MARTINS, 2005a). Para tanto, a dualidade do CEO é outro mecanismo de governança corporativa analisado. A “dualidade do CEO é a prática em que o Chief Executive Officer (CEO) exerce tanto a função de presidente da empresa quanto a de presidente do seu Conselho de Administração" (COSTA; MARTINS, 2019, p. 404). Com base na teoria da agência, "os defensores da não dualidade do CEO sugerem que a dualidade do CEO diminui o papel de monitoramento do conselho de administração sobre o gerente executivo, o que, por sua vez, pode ter um efeito negativo no desempenho financeiro" (WAHBA, 2015, p. 23). Esta teoria conforme Moscu (2013, p. 156) “sugere que a dualidade do CEO é ruim para o desempenho, pois compromete o monitoramento e o controle do CEO" e argumenta "que estas duas funções devem ser exercidas por pessoas diferentes" (COSTA; MARTINS, 2019, p. 404).

Nesse sentido, a dualidade do CEO pode ser considerada prejudicial para a empresa, pois a mesma pessoa monitora suas próprias ações (AMARAL-BAPTISTA; KLOTZLE; MELO, 2011). “Essa situação dificulta a avaliação correta do desempenho da empresa e pode levar a um desempenho inferior da empresa a longo prazo; esse arranjo concentra muito poder nas mãos de um executivo e pode levar ao 
baixo desempenho" (MOSCU, 2013, p. 158).

Estudos revelaram um efeito positivo da dualidade do CEO sobre o ROE (AMARAL-BAPTISTA; KLOTZE; MELO, 2011; UJUNWA, 2012) e negativo no ROE (UADIALE, 2010), ROA (EHIKIOVA, 2009; UJUNWA, 2012) e $Q$ de Tobin (EHIKIOVA, 2009; UJUNWA, 2012). Por outro lado, estudos encontraram uma relação sem significância entre a dualidade do CEO e o ROA (AMARAL-BAPTISTA; KLOTZE; MELO, 2011; MOSCU, 2013; DANI et al., 2017), ROE (MOSCU, 2013; EHIKIOVA, 2009) e $Q$ de Tobin (ANDRADE et al., 2009). Diante destes resultados pode-se constatar que a relação entre a dualidade do CEO e o desempenho empresarial é mista e inconclusiva (UADIALE, 2010), portanto, formulou-se a segunda hipótese do estudo: H2: a dualidade do CEO reduz o desempenho empresarial.

As empresas Big Four requisitam profissionais com níveis elevados de competência e compromisso com o trabalho (EDGLEY; SHARMA; ANDERSON-GOUGH, 2016). Mayoral e Segura (2007) afirmam que as firmas de auditoria Big Four cobram por serviços de qualidade realizados nos trabalhos de auditoria. No que tange esta qualidade, Owhoso e Weickgenannt (2009) ressaltam que as empresas de auditoria podem controlar esta qualidade, por meio do oferecimento de avanços individuais para os auditores, a partir de treinamentos, cursos, fazendo com que estes apresentam desempenho competente diante da equipe. Ge e Liu (2015) constataram que havia um menor risco de inadimplência nas empresas que eram auditadas por uma Big Four, fato que pode impulsionar o desempenho das empresas.

Nesse sentido, as empresas serem auditadas por uma Big Four, representa outro mecanismo de governança corporativa, visto que estas empresas de auditoria buscam a excelência das demonstrações contábeis divulgadas. Entende-se que se a empresa foi auditada por uma Big Four, isso pode apresentar impactos positivos no desempenho. Contudo, não se encontraram evidências que suportam tal relação, sendo uma lacuna identificada na literatura. Diante do exposto, propõem-se a seguinte hipótese: H3: empresas auditadas por Big Four aumentam o desempenho empresarial.

O comitê de auditoria tem sido considerado um instrumento de supervisão fundamental na preservação da integridade do mercado de capitais e responsável pela supervisão do processo de preparação 
e divulgação das informações financeiras, integridade dos controles internos e elo de comunicação com os auditores independentes. Sua missão é proteger os interesses de todas as partes interessadas (PELEIAS; SEGRETI; COSTA, 2009). Um comitê de auditoria atuante permite que a companhia tenha uma supervisão mais ativa, o que contribui para assegurar que os sistemas de controles internos funcionarão de forma efetiva (IBGC, 2009).

A CVM (2002) ressalta que um comitê de auditoria, composto por membros do conselho de administração com experiência em finanças e incluindo pelo menos um conselheiro que represente os minoritários, deve supervisionar o relacionamento com o auditor. De acordo com o IBGC (2009), a auditoria independente é um mecanismo de governança corporativa de grande importância para as partes interessadas, pois tem como principais atribuições examinar as demonstrações contábeis e desenvolver um parecer quanto à adequação de sua forma de elaboração. Denota-se que um tamanho maior do comitê de auditoria fornece um monitoramento mais rigoroso nas organizações (HSU; PETCHSAKULWONG, 2010), logo, tende a afetar o desempenho empresarial. Hsu e Petchsakulwong (2010) encontraram uma relação negativa entre o tamanho do comitê de auditoria e a eficiência do desempenho. A partir do exposto, formulou-se a quarta hipótese do estudo: $\mathrm{H} 4$ : a presença de um comitê de auditoria aumenta o desempenho empresarial.

A CVM (2002) defende que o conselho de administração deve ter o maior número de membros independentes e que o cargo de diretor deste conselho deve ser diferente do CEO. O IBGC (2009) recomenda que o conselho deva ter uma composição mínima de 5 e, no máximo, 11 membros. Silveira, Barros e Famá (2003) corroboram enfatizando que a efetividade do conselho diminui na medida em que este ultrapassa certo número de membros. Para tanto, o tamanho do conselho pode ser considerado outro relevante mecanismo de governança corporativa. De acordo com Ehikioya (2009), o número do conselho de administração apresenta influência no desempenho empresarial, pois este conselho possui a responsabilidade de gerenciar a empresa e suas atividades. Um tamanho grande do conselho permite que este colete mais informações, o que poderá impactar o 
desempenho (AKPAN; AMRAN, 2014).

Evidências empíricas sobre a influência do tamanho do conselho no desempenho revelaram resultados mistos. No que tange ao ROA, o tamanho do conselho se relacionou positivamente (EHIKIOVA, 2009; DANI et al., 2017), negativamente (ADAMS; FERREIRA, 2009; UJUNWA, 2012) e não apresentou influência (AMARAL-BAPTISTA; KLOTZE; MELO, 2011; DARMADI, 2011). Em relação ao ROE, os achados também revelaram uma relação positiva (UADIALE, 2010), negativa (EHIKIOVA, 2009) e sem significância (AMARAL-BAPTISTA; KLOTZE; MELO, 2011). Estudos também encontraram um efeito positivo (ANDRADE et al., 2009; DARMADI, 2011), negativo (ADAMS; FERREIRA, 2009) e sem relação (EHIKIOVA, 2009) entre o tamanho do conselho e o $Q$ de Tobin. Deste modo, elaborou-se a seguinte hipótese: $\mathrm{H} 5$ : a maior proporção de executivos no conselho de administração reduz o desempenho empresarial.

Os conselhos de administração desempenham diversos papéis e dentre os fatores que determinam a capacidade de um conselho desempenhar efetivamente várias funções é o tamanho do conselho e a qualificação educacional dos membros do conselho (GAUR; BATHULA; SINGH, 2015). Um conselho de administração conseguirá dedicar energias suficientes a diversas funções, quando possuir membros suficientes no conselho para assumir tais responsabilidades e estiverem qualificados para desempenhar suas tarefas com eficácia (O'SULLIVAN 2009). A qualificação dos membros do conselho pode ser um indicativo da sua competência, pois o seu funcionamento eficaz exige membros com qualificações adequadas, altos níveis de capacidade intelectual e experiência (GAUR; BATHULA; SINGH, 2015).

A “boa governança corporativa se manifesta nas qualificações (em termos de profissão e experiência) dos membros do conselho de administração e da administração da empresa" (UJUNWA, 2012, p. 657). Logo, conselheiros com qualificação, teoricamente possuem conhecimentos, experiências e competências gerenciais e administrativas na condução dos negócios (UJUNWA, 2012; AKPAN; AMRAN, 2014; GAUR; BATHULA; SINGH, 2015), o que pode impactar no desempenho empresarial. De acordo com Ujunwa (2012), o conselho de administração que possui membros com expertises ligadas a área contábil e administrativa podem se beneficiar dos conhecimentos e 
experiências que estes membros possuem em relatórios financeiros e realizar suas atividades com vistas a alavancar o desempenho. Estudos analisaram a influência da expertise do conselho no desempenho. Os resultados apontaram uma relação positiva entre a expertise e o ROA (UJUNWA, 2012; DANI et al., 2017) e sem significância no ROA (EHIKIOVA, 2009). Ehikiova (2009) revelou que a expertise se relacionou positivamente com o ROE e não apresentou significância com o $Q$ de Tobin. Diante dos argumentos, propõem-se a hipótese: H6: a presença de executivos no conselho de administração com expertise financeira e administrativa aumenta o desempenho empresarial.

Tradicionalmente, "os conselhos são compostos apenas por membros do sexo masculino. A presença de mulheres no conselho leva à diversidade de gênero" (UJUNWA, 2012, p. 660). A representação de mulheres no conselho de administração é baixa (ADAMS; FERREIRA, 2009; DAMARDI, 2011). Contudo, "muitas propostas de reforma da governança enfatizam explicitamente a importância da diversidade de gênero na sala de reuniões" (ADAMS; FERREIRA, 2009 , p. 291). Dentre estas iniciativas, a maioria baseia-se na visão de que a "presença de mulheres nos conselhos de administração poderia afetar de maneira significativa a governança das empresas" (ADAMS; FERREIRA, 2009, p. 291).

Deste modo, "a implicação é que a presença de mulheres no conselho, pode ser percebida pelos acionistas que uma mudança significativa está a caminho e tornando-as mais confiantes no sucesso da empresa, o que resulta em aumento no preço das ações" (UJUNWA, 2012, p. 660-661). Evidências indicaram que o gênero do conselho de administração se relaciona negativamente com o ROA (DARMADI, 2011; UJUNWA, 2012; DANI et al., 2017) e Adams e Ferreira (2009) não encontraram uma relação significativa entre esta relação. O gênero do conselho também apresentou impactos negativos no $Q$ de Tobin (ADAMS; FERREIRA, 2009; DARMADI, 2011). Não foram encontradas evidências de estudos que analisaram a relação entre o gênero do conselho e o desempenho medido pelo ROE. Com base no exposto, desenvolveu-se a seguinte hipótese: H7: a presença de mulheres no conselho de administração aumenta o desempenho empresarial.

A Figura 1 apresenta o modelo teórico da pesquisa e sintetiza 
as relações esperadas a partir das sete hipóteses propostas.

\section{Figura 1 - Modelo teórico de análise e visão geral das hipóteses de pesquisa}

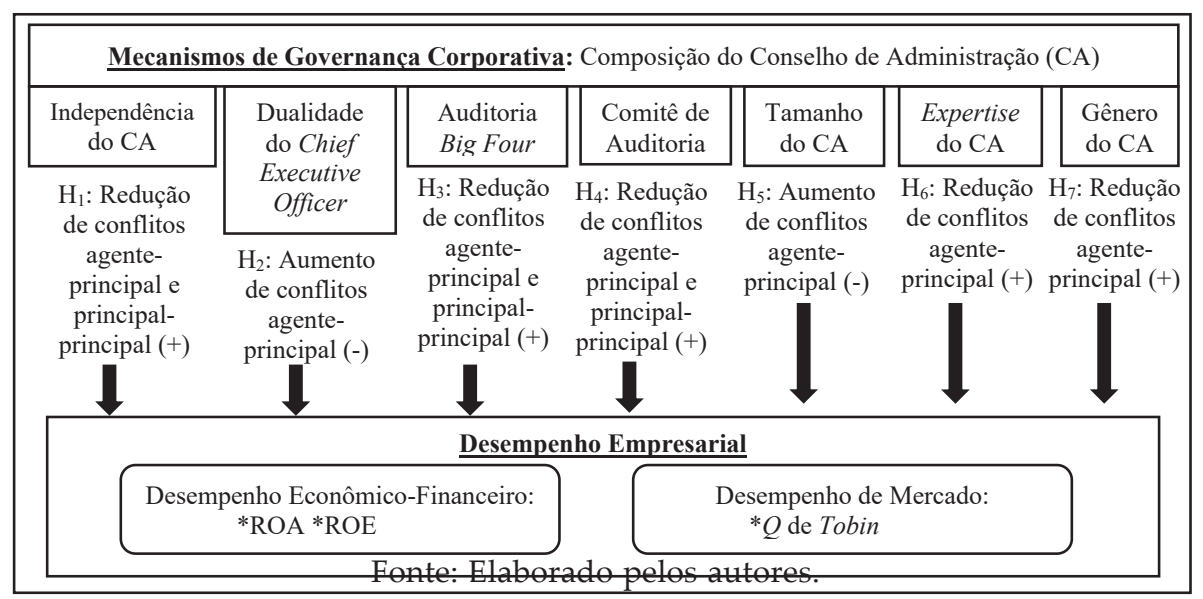

\section{MÉTOdo E PROCEDIMENTOS DA PESQUISA}

\subsection{Delineamento da pesquisa}

Esta pesquisa carateriza-se como descritiva, documental e quantitativa. Configura-se quanto aos objetivos como descritiva, pois tem como objetivo descrever as relações entre as variáveis dos mecanismos de governança corporativa e o desempenho de empresas brasileiras listadas nos níveis 1, 2 e novo mercado. Em relação aos procedimentos, este estudo classifica-se como documental, pois as informações referentes ao desempenho empresarial e variável de controle foram coletadas na Thomson One Banker ${ }^{\circledR}$ e as variáveis de governança corporativa foram coletadas no Formulário de Referência e base de dados do Laboratório de Finanças e Risco da FEA/USP. No que tange a abordagem do problema, esta pesquisa é de natureza quantitativa por utilizar a técnica de regressão para quantificar as informações objeto de estudo.

\subsection{População e amostra}


A população é composta pelas companhias abertas listadas nos níveis de governança corporativa: Nível 1, Nível 2 e Novo Mercado da Brasil, Bolsa e Balcão (B3), exceto as empresas classificadas no setor econômico "Financeiro e Outros", visto as características singulares de suas atividades e coforme procedimentos adotados por Andrade et al. (2009).

Optou-se por analisar as empresas desses três níveis de governança corporativa, pelo fato destas empresas terem o mais elevado padrão de governança corporativa (DANI et al., 2017). Para a amostra foram selecionadas as empresas que continham todas as informações necessárias para a realização do estudo. Justifica-se a exclusão de empresas com dados incompletos com o intuito de encontrar uma amostra equilibrada e para melhorar a inferência nos resultados (COSTA; MARTINS, 2019). O período analisado compreendeu os anos de 2014 a 2018. A Tabela 1 apresenta o número de empresas pertencentes à população e amostra.

Tabela 1 - População e amostra da pesquisa

\begin{tabular}{l|c|c|c}
\hline $\begin{array}{c}\text { Níveis de Governança } \\
\text { Corporativa }\end{array}$ & População & $\begin{array}{c}\text { Empresas sem } \\
\text { informação em } \\
\text { todos os anos }\end{array}$ & $\begin{array}{c}\text { Amostra } \\
\text { Final }\end{array}$ \\
\hline Nível 1 & 20 & 1 & 19 \\
\hline Nível 2 & 14 & - & 14 \\
\hline Novo Mercado & 111 & 7 & 104 \\
\hline Total & $\mathbf{1 4 5}$ & $\mathbf{8}$ & $\mathbf{1 3 7}$ \\
\hline
\end{tabular}

Fonte: Dados da pesquisa.

Conforme a Tabela 1, das 145 empresas que constituíram a população do estudo, 137 fizeram parte da amostra no período analisado, perfazendo um total de 685 observações. No que tange à classificação das empresas da amostra nos setores de atuação, conforme a Tabela 2 é possível verificar que a maioria da amostra é composta por empresas do setor de Consumo Cíclico, seguido de Utilidade Pública e Bens Industriais.

Tabela 2 - Empresas da amostra por setor 


\begin{tabular}{l|c|c}
\hline \multicolumn{1}{c|}{ Setor } & Amostra & \% Amostra \\
\hline Bens Industriais & 23 & $16,79 \%$ \\
\hline Consumo Cíclico & 45 & $32,84 \%$ \\
\hline Consumo Não Cíclico & 13 & $9,49 \%$ \\
\hline Materiais Básicos & 12 & $8,76 \%$ \\
\hline Petróleo Gás e Combustível & 5 & $3,65 \%$ \\
\hline Saúde & 11 & $8,03 \%$ \\
\hline Tecnologia da Informação & 2 & $1,46 \%$ \\
\hline Utilidade Pública & 25 & $18,25 \%$ \\
\hline Outros Total & 1 & $0,73 \%$ \\
\hline & $\mathbf{1 3 7}$ & $\mathbf{1 0 0} \%$ \\
\hline
\end{tabular}

Fonte: Dados da pesquisa.

\subsection{Constructos da pesquisa}

Para operacionalizar a pesquisa, foram utilizadas três variáveis para mensurar o desempenho empresarial. ROA e ROE referem-se ao desempenho econômico-financeiro e a variável $Q$ de Tobin visa medir o desempenho de mercado. Também foram utilizadas sete variáveis para mensurar os mecanismos de governança corporativa e uma variável de controle. No Quadro 1 apresenta-se as variáveis analisadas no estudo.

\section{Quadro 1 - Variáveis analisadas}

\begin{tabular}{|c|c|c|c|c|}
\hline \multicolumn{2}{|c|}{ Variáveis dependentes } & Operacionalização & Coleta de & Autores \\
\hline \multirow{3}{*}{ 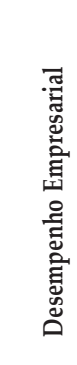 } & $\begin{array}{l}\text { Rentabilidade } \\
\text { do Ativo Total } \\
\text { (ROA) }\end{array}$ & $\frac{\text { Lucro Líquido }}{\text { Ativo Total }}$ & \multirow{3}{*}{ 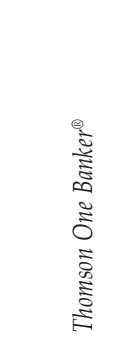 } & $\begin{array}{l}\text { Adams e Ferreira (2009); Ehikiova (2009); Darma- } \\
\text { di (2011); Amaral-Baptista, Klotze e Melo (2011); } \\
\text { Ujunwa (2012); Moscu (2013); Gaur, Bathula e } \\
\text { Singh (2015); Costa e Martins (2019). }\end{array}$ \\
\hline & $\begin{array}{l}\text { Rentabilidade } \\
\text { do Patrimônio } \\
\text { Líquido (ROE) }\end{array}$ & $\frac{\text { Lucro Líquido }}{\text { Patrimônio Líquido }}$ & & $\begin{array}{l}\text { Ehikiova (2009); Uadiale (2010); Amaral-Baptista, } \\
\text { Klotze e Melo (2011); Caixe e Krauter (2013); Mos- } \\
\text { cu (2013); Wahba (2015); Costa e Martins (2019). }\end{array}$ \\
\hline & $\begin{array}{l}Q \text { de Tobin } \\
(Q T)\end{array}$ & $\frac{\mathrm{VMA}^{*}+\mathrm{D}^{* *}}{\text { Ativo Total }}$ & & $\begin{array}{l}\text { Adams e Ferreira (2009); Ehikiova (2009); Darma- } \\
\text { di (2011); Caixe e Krauter (2013); Wahba (2015). }\end{array}$ \\
\hline
\end{tabular}


Mecanismos de Governança Corporativa e o Desempenho Econômico-Financeiro e de Mercado de Empresas Brasileiras listadas no Nível 1, Nível 2 e Novo Mercado

\begin{tabular}{|c|c|c|c|c|}
\hline \multicolumn{2}{|c|}{ Variáveis independentes } & \multirow{2}{*}{$\begin{array}{l}\text { Operacionalização } \\
\text { A razão entre o nú- } \\
\text { mero de membros } \\
\text { independentes e o } \\
\text { tamanho do conselho. }\end{array}$} & \multirow{2}{*}{\begin{tabular}{|c|}
$\begin{array}{l}\text { Coleta de } \\
\text { dados }\end{array}$ \\
Formulário \\
de Referência/ \\
Ítem $12.6 / 8$ e \\
\end{tabular}} & \multirow{2}{*}{$\begin{array}{l}\text { Autores } \\
\text { Adams e Ferreira (2009); Andrade et al. (2009); Hsu } \\
\text { e Petchsakulwong (2010); Uadiale (2010); Akpan e } \\
\text { Amran (2014); Gaur, Bathula e Singh (2015). }\end{array}$} \\
\hline \multirow{7}{*}{ 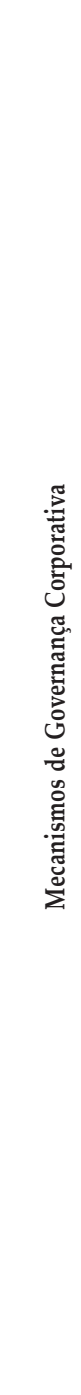 } & $\begin{array}{l}\text { Independência } \\
\text { do Conselho de } \\
\text { Administração } \\
\text { (ICA) }\end{array}$ & & & \\
\hline & $\begin{array}{l}\text { Dualidade do } \\
\text { Diretor (DD) }\end{array}$ & $\begin{array}{l}\text { Variável dummy, } 1 \\
\text { se o CEO é o presi- } \\
\text { dente do conselho } \\
\text { de administração, } 0 \\
\text { caso contrário. }\end{array}$ & $\begin{array}{l}\text { do Laborató- } \\
\text { rio de Finan- } \\
\text { ças e Risco da } \\
\text { FEA/USP. }\end{array}$ & $\begin{array}{l}\text { Andrade et al. (2009); Ehikiova (2009); Uadiale } \\
\text { (2010); Amaral-Baptista, Klotze e Melo (2011) } \\
\text { Ujunwa (2012); Moscu (2013); Wahba (2015); Costa } \\
\text { e Martins (2019). }\end{array}$ \\
\hline & $\begin{array}{l}\text { Auditoria Big } \\
\text { Four }(\mathrm{A} B F)\end{array}$ & $\begin{array}{l}\text { Variável dummy, } 1 \text { se } \\
\text { a empresa foi audita- } \\
\text { da por uma Big Four, } \\
0 \text { caso contrário. }\end{array}$ & \multirow{2}{*}{$\begin{array}{c}\text { Formulário de } \\
\text { Referência e } \\
\text { base de dados } \\
\text { do Laborató- } \\
\text { rio de Finan- } \\
\text { ças e Risco da } \\
\text { FEA/USP. }\end{array}$} & Ge e Liu (2015). \\
\hline & $\begin{array}{l}\text { Comitê de Au- } \\
\text { ditoria }(\mathrm{CA})\end{array}$ & $\begin{array}{l}\text { Variável dummy, } 1 \\
\text { se a empresa possui } \\
\text { comitê de auditoria, } \\
0 \text { caso contrário. }\end{array}$ & & Hsu e Petchsakulwong (2010). \\
\hline & $\begin{array}{l}\text { Tamanho do } \\
\text { Conselho de } \\
\text { Administração } \\
\text { (TCA) }\end{array}$ & $\begin{array}{l}\text { Logaritmo Natural } \\
\text { do número total de } \\
\text { membros no con- } \\
\text { selho. }\end{array}$ & $\begin{array}{l}\text { FR/Ítem } 13.2 \text { e } \\
\text { base do Labora- } \\
\text { tório de Finan- } \\
\text { ças e Risco da } \\
\text { FEA/USP. }\end{array}$ & $\begin{array}{l}\text { Adams e Ferreira (2009); Andrade et al. (2009), } \\
\text { Ehikiova (2009); Uadiale (2010); Darmadi (2011) } \\
\text { Amaral-Baptista, Klotze e Melo (2011); Ujunwa } \\
\text { (2012); Akpan e Amran (2014); Gaur, Bathula e } \\
\text { Singh (2015); Costa e Martins (2019). }\end{array}$ \\
\hline & $\begin{array}{l}\text { Expertise do } \\
\text { Conselho de } \\
\text { Administração } \\
\text { (ECA) }\end{array}$ & $\begin{array}{l}\text { Razão entre o nú- } \\
\text { mero de membros } \\
\text { com graduação ou } \\
\text { pós-graduação em } \\
\text { Ciências Contábeis } \\
\text { ou Administração } \\
\text { ou Economia e o } \\
\text { número total de } \\
\text { conselheiros. }\end{array}$ & \multirow[t]{2}{*}{$\begin{array}{l}\text { Formulário } \\
\text { de Referência/ } \\
\text { Ítem } 12.6 / 8 \text { e } \\
\text { base de dados } \\
\text { do Laborató- } \\
\text { rio de Finan- } \\
\text { ças e Risco da } \\
\text { FEA/USP. }\end{array}$} & $\begin{array}{l}\text { Ehikiova (2009); Ujunwa (2012); Akpan e Amran } \\
\text { (2014); Gaur, Bathula e Singh (2015). }\end{array}$ \\
\hline & $\begin{array}{l}\text { Gênero do Con- } \\
\text { selho de Admi- } \\
\text { nistração (GCA) }\end{array}$ & $\begin{array}{l}\text { Razão entre o núme- } \\
\text { ro de mulheres no } \\
\text { conselho e o número } \\
\text { total de conselheiros }\end{array}$ & & $\begin{array}{l}\text { Adams e Ferreira (2009); Darmadi (2011); Ujunwa } \\
\text { (2012); Akpan e Amran (2014). }\end{array}$ \\
\hline \multicolumn{2}{|c|}{ Variável de controle } & Operacionalização & $\begin{array}{c}\text { Coleta de } \\
\text { dados }\end{array}$ & Autores \\
\hline \multicolumn{2}{|c|}{$\begin{array}{l}\text { Tamanho da empresa } \\
\text { (TAM) }\end{array}$} & $\begin{array}{l}\text { Logaritmo natural } \\
\text { do ativo total da } \\
\text { empresa. }\end{array}$ & $\begin{array}{c}\text { Thomson One } \\
\text { Banker }^{\circledR}\end{array}$ & $\begin{array}{l}\text { Darmadi (2011); Caixe e Krauter (2013); Moscu } \\
\text { (2013); Wahba (2015); Costa e Martins (2019). }\end{array}$ \\
\hline
\end{tabular}

*VMA = Valor de mercado das ações negociadas em bolsa;

${ }^{* *} \mathrm{D}=$ Passivo circulante - Ativo circulante + Estoques - Passivo não circulante.

Fonte: Dados da pesquisa.

Organizações em contexto, São Bernardo do Campo, ISSNe 1982-8756 • Vol. 17, n. 33, jan.-jun. 2021155 


\subsection{Procedimentos de coleta e análise dos dados}

As informações referentes ao desempenho empresarial (ROA, ROE e $Q$ de Tobin) e tamanho da empresa foram coletadas na Thomson One Banker ${ }^{\circledR}$. As informações sobre os mecanismos de governança corporativa foram coletadas no Formulário de Referência divulgado pelas empresas no sítio da B3 e na base de dados do Laboratório de Finanças e Risco da FEA/USP que disponibiliza dados relativos a governança corporativa de empresas listadas na B3. A coleta dos dados foi realizada nos meses de janeiro a fevereiro de 2020.

Após a coleta dos dados, as informações foram tabuladas e importadas no software SPSS ${ }^{\circledR}$ para a realização do tratamento dos dados. Inicialmente realizou-se o teste de normalidade, na sequência, o teste Fator de Inflação de Variância (VIF), posteriormente, a correlação entre as variáveis e por fim, a regressão linear múltipla das relações investigadas.

Ressalta-se que para a realização da regressão linear múltipla se faz necessário o atendimento aos cinco pressupostos da regressão: Normalidade dos resíduos (Kolmogorov-Smirnov), Heterocedasticidade (Pesaran-Pesaran), Linearialidade dos coeficientes (ANOVA), Auto-Correlação (Durbin-Watson) e Multicolinearidade (VIF) (FÁVERO et al., 2009). Realizou-se o teste de Normalidade com vistas a identificar qual a Correlação que deve ser aplicada nos dados (Correlação de Spearman ou Pearson). Na sequência, aplicou-se nos dados o teste de VIF para verificar possíveis problemas de multicolinearidade entre os mecanismos de governança corporativa pesquisados. De acordo com Gujarati e Porter (2011), a identificação de multicolinearidade entre as variáveis, não significa problemas do modelo, no entanto, uma elevada presença de multicolinearidade entre as variáveis pode ocasionar um aumento no termo do erro. Posteriormente, efetuou-se a correlação de spearman para verificar uma possível associação entre as variáveis. Esta associação apenas pode ser confirmada a partir dos resultados da regressão linear múltipla que foi aplicada na sequência nos dados.

Três modelos de regressão foram elaborados para analisar a relação entre os mecanismos de governança corporativa e o desempenho de empresas pertencentes ao nível 1, nível 2 e novo mercado, conforme apresenta-se a seguir: 


$$
\begin{gathered}
\mathrm{ROA}=\beta_{0}+\beta_{1} \mathrm{ICA}+\beta_{2} \mathrm{DD}+\beta_{3} \mathrm{ABF}+\beta_{4} \mathrm{CA}+\beta_{5} \mathrm{TCA}++\beta_{6} \mathrm{ECA}+\beta_{7} \mathrm{GCA}+\stackrel{(1)}{8}_{8} \\
\mathrm{TAM}+\beta_{9} \mathrm{SET}+\varepsilon
\end{gathered}
$$

$\mathrm{ROE}=\beta_{0}+\beta_{1} \mathrm{ICA}+\beta_{2} \mathrm{DD}+\beta_{3} \mathrm{ABF}+\beta_{4} \mathrm{CA}+\beta_{5} \mathrm{TCA}++\beta_{6} \mathrm{ECA}+\beta_{7} \mathrm{GCA}+\beta_{8}$ $\mathrm{TAM}+\beta_{9} \mathrm{SET}+\varepsilon$

$$
\begin{gathered}
\mathrm{Q} \text { de Tobin }=\beta_{0}+\beta_{1} \mathrm{ICA}+\beta_{2} \mathrm{DD}+\beta_{3} \mathrm{ABF}+\beta_{4} \mathrm{CA}+\beta_{5} \mathrm{TCA}++\beta_{6} \mathrm{ECA}+\beta_{7} \\
\mathrm{GCA}+\beta_{8} \mathrm{TAM}+\beta_{9} \mathrm{SET}+\varepsilon
\end{gathered}
$$

Ressalta-se que os três modelos de regressão foram analisados para as empresas que compreendem os segmentos de governança corporativa: nível 1, nível 2 e novo mercado. Assim, três regressões foram rodadas para cada grupo de empresas da amostra. Destaca-se que apenas foram analisados os modelos (ROA, ROE e $Q$ de Tobin) para cada amostra de empresas que obtiveram um $R^{2}$ e $R^{2}$ ajustado acima de 0,50, procedimentos estes também utilizados por Dani et al. (2017). Conforme os autores o parâmetro de 0,50 em relação ao poder de explicação do modelo é "considerado bom para fins de análise" (DANI et al., 2017).

\section{ANÁlise E INTERPRETAÇÃo dos RESUltados}

\subsection{Resultados do teste de normalidade e VIF}

Antes de analisar a relação entre os mecanismos de governança corporativa e o desempenho de empresas brasileiras, por meio da regressão linear múltipla, realizou-se o teste de normalidade dos dados, o teste VIF e, posteriormente a correlação entre as variáveis. O teste de normalidade revelou que os dados analisados não possuem uma distribuição normal, pois os testes Kolmogorov-Smirnov e Shapiro Wilk apresentaram-se significativos ao nível de 5\%. Para tanto, efetuou-se a correlação de spearman, com vistas a identificar a correlação existente entre as variáveis analisadas e os possíveis problemas de multicolineariedade (FÁVERO et al., 2009). Para identificar possíveis problemas de multicolinearidade, efetuou-se o teste VIF, que "é uma medida de quanto a variância de cada coeficiente de regressão estimado aumenta devido a multicolinearidade" (FÁVERO et al., 2009, p. 359). 
Tabela 3 - Teste Fator de Inflação de Variância (VIF)

\begin{tabular}{l|c|c|c|c|c|c|c|c}
\hline Variáveis & ICA & DD & ABF & CA & TCA & ECA & GCA & TAM \\
\hline Tolerância & 0,862 & 0,993 & 0,969 & 0,914 & 0,583 & 0,930 & 0,951 & 0,583 \\
\hline VIF & 1,160 & 1,007 & 1,032 & 1,094 & 1,016 & 1,075 & 1,051 & 1,015 \\
\hline
\end{tabular}

Fonte: Dados da Pesquisa.

O teste VIF revelou que as variáveis independentes não possuem problemas de multicolinearidade, pois o maior VIF identificado foi de 1,160. Valores VIF acima de 10 revelam problemas de multicolinearidade nas variáveis (GUJARATI; PORTER, 2011).

4.2 Resultados da correlação entre as variáveis

Nesta seção realizou-se o cálculo da intensidade e o sentido das correlações entre as variáveis pesquisadas, por meio do coeficiente de correlação de spearman. Destaca-se que esta correlação não sugere necessariamente uma relação de causa e efeito entre as variáveis, mas sim, possibilita a identificação do grau de associação entre cada uma das variáveis. A Tabela 4 mostra a matriz de correlação entre as variáveis.

Tabela 4 - Correlação de Spearman entre as variáveis

\begin{tabular}{|c|c|c|c|c|c|c|c|c|c|c|c|}
\hline $\begin{array}{c}\text { Variá- } \\
\text { veis }\end{array}$ & ROA & ROE & $Q T$ & ICA & DD & $\mathrm{ABF}$ & $\mathrm{CA}$ & TCA & ECA & GCA & TAM \\
\hline $\mathrm{ROA}$ & 1 &, $170^{* *}$ &,$- 244^{* *}$ &,$- 115^{* *}$ & ,053 &, $178^{* *}$ & ,059 & ,043 &,$- 118^{* *}$ & ,070 & ,000 \\
\hline ROE & & 1 &,$- 146^{* *}$ &,$- 132^{* *}$ & ,047 & $142^{* *}$ & ,033 & ,048 &,$- 077^{*}$ & ,066 & ,034 \\
\hline$Q T$ & & & 1 & $103^{* *}$ &,- 043 & ,044 &,- 008 &,$- 219 * *$ & $139 * *$ &,- 007 &,$- 285^{* *}$ \\
\hline ICA & & & & 1 &,- 005 &,- 047 &,$- 128^{* *}$ & $107^{* *}$ &,- 064 &,- 028 &,$- 235^{* *}$ \\
\hline $\mathrm{DD}$ & & & & & 1 &,- 029 & ,021 &,- 035 &,- 029 &,- 026 &,- 006 \\
\hline $\mathrm{ABF}$ & & & & & & 1 & ,045 & , $077^{*}$ & ,011 & $107^{* *}$ &, 065 \\
\hline $\mathrm{CA}$ & & & & & & & 1 & $102^{* *}$ & ,051 & ,044 & $229^{* *}$ \\
\hline TCA & & & & & & & & 1 &,$- 246^{* *}$ & $198^{* *}$ &, $525^{* *}$ \\
\hline ECA & & & & & & & & & 1 &,- 026 &,- 051 \\
\hline GCA & & & & & & & & & & 1 & , $056^{*}$ \\
\hline TAM & & & & & & & & & & & 1 \\
\hline
\end{tabular}

**A correlação é significativa no nível de $1 \%$. * A correlação é significativa no nível de $5 \%$.

Fonte: Dados da pesquisa. 
A partir dos resultados da Tabela 4 denota-se que não há problemas de multicolinearidade nas variáveis, pois não se obteve uma correlação entre as variáveis maior ou igual a 0,70, conforme a orientação de Hair et al. (2005). Portanto, verifica-se que, em geral, a mulcolinearidade não afeta os modelos estimados, visto que as variáveis não estão fortemente correlacionadas. Além disso, a correlação de spearman entre as variáveis indicou a existência de correlação entre as variáveis dependentes (ROA, ROE e $Q$ de Tobin) e as independentes (mecanismos de governança corporativa).

Mais precisamente, o ROA apresentou uma correlação positiva e significativa com o ROE e a empresa ter sido auditada por uma empresa de auditoria Big Four. Estes resultados sugerem que aumentos no ROE e auditorias realizadas nas empresas por uma Big Four, consequentemente elevam o desempenho avaliado pelo ROA. Darmadi (2011) destaca que o tamanho da empresa está positivamente correlacionado ao ROA, fornecendo evidências de que empresas maiores tendem a mostrar melhor desempenho, achado este que difere desta pesquisa.

Por outro lado, tanto o ROA, quanto o ROE apresentaram uma relação negativa e significativa com o $Q$ de Tobin, independência e a expertise do conselho de administração. Tais resultados sugerem que quanto mais independente estiver a composição do conselho de administração em relação ao percentual de conselheiros externos, quanto maior é o desempenho de mercado e a expertise do conselho na área de finanças, menor será a probabilidade de as empresas auferirem desempenho medido pelo ROA e ROE. A rentabilidade do patrimônio líquido também revelou uma correlação positiva apenas com a variável $A B F$, o que sugere que empresas auditadas por Big Four obtêm melhor desempenho empresarial em relação ao ROE. Este resultado diverge dos encontrados por Uadiale (2010), pois os autores constataram que o ROE está positivamente correlacionado com o tamanho do conselho de administração.

No que tange ao desempenho de mercado, os achados indicaram uma correlação positiva e significativa com a independência e a expertise do conselho de administração. Esta constatação sugere que quanto mais independente for a composição do conselho em relação ao percentual de conselheiros externos e os membros do 
conselho tiverem expertise na área de finanças, maior tende a ser o desempenho empresarial avaliado pelo $Q$ de Tobin.

Entretanto, menor tende a ser o desempenho de mercado, a partir do momento que as empresas do nível 1, 2 e novo mercado tiveram conselhos de administração com poucos membros e o tamanho da empresa medido pelo ativo total ser relativamente baixo, visto que o tamanho do conselho de administração e da empresa apresentaram uma correlação negativa com o desempenho de mercado. Os resultados da pesquisa de Damardi (2011) não se assemelham com os achados desta pesquisa, pois constataram uma relação negativa entre gênero do conselho e $Q$ de Tobin e relação positiva entre tamanho do conselho e desempenho de mercado, o que sugere que um tamanho maior do conselho provavelmente pertencia a empresas com ativos maiores e maior desempenho de mercado.

Os resultados da variável ROA se diferem dos encontrados por Dani et al. (2017), pois os autores não encontraram correlações entre o ROA e independência e expertise do conselho. Quanto ao ROE também se diferem dos resultados do estudo de Dani et al. (2017), visto que encontraram uma relação positiva entre ROE e tamanho do conselho de administração e no presente estudo não foi constatada esta correlação. Em relação ao $Q$ de Tobin, nenhuma evidência encontrada neste estudo para empresas com a mesma amostra da pesquisa realizada por Dani et al. (2017), no caso empresas do novo mercado, foram observadas por estes autores, como por exemplo, a correlação entre o $Q$ de Tobin e a independência, tamanho e expertise do conselho de administração. Este fato revela que o comportamento do desempenho de mercado em períodos diferentes pode apresentar diferenças nos resultados para empresas com níveis elevados de governança corporativa.

Sobre as variáveis do conselho de administração, que se referem aos mecanismos de governança corporativa pode-se apresentar os principais resultados:

Quanto maior for o tamanho do conselho, maior será a sua independência, ou seja, os conselhos tendem a aumentar de tamanho a partir da entrada de novos conselheiros externos (relação positiva entre independência e tamanho do conselho). Este resultado tam- 
bém foi constatado por Andrade et al. (2009). Já Dani et al. (2017) não encontraram correlação entre a independência e o tamanho do conselho. Andrade et al. (2009) evidenciaram relação negativa entre a independência do conselho e dualidade do diretor, o que sugere que quanto mais independente estiver a composição do conselho, menor será a probabilidade de os cargos de diretor executivo e presidente do conselho serem ocupados pela mesma pessoa.

A dualidade do diretor não apresentou correlação com nenhuma das variáveis relacionadas aos mecanismos de governança corporativa. Os resultados de Dani et al. (2017) revelaram que a dualidade do diretor apenas se relaciona com o gênero do conselho de administração. O estudo de Costa e Martins (2019) evidenciou que a dualidade de funções está negativamente correlacionada com o tamanho do conselho de administração.

O tamanho do conselho se correlacionou positivamente com a expertise e negativamente com o gênero, resultados estes que se diferem dos achados de Dani et al. (2017). Andrade et al. (2009) encontraram uma relação negativa entre o tamanho do conselho e a dualidade do diretor, o que indica que quanto maior for o tamanho do conselho, menor será a probabilidade de a mesma pessoa ocupar os cargos de diretor executivo e diretor do conselho.

Contudo, os resultados da correlação entre as variáveis apenas podem ser confirmados com a realização da regressão linear múltipla, conforme apresentado na sequência.

\subsection{Resultados da regressão: empresas nível 1}

Na Tabela 5, apresentam-se os resultados para as empresas pertencentes ao nível 1. 
Tabela 5 - Resultados da regressão - Empresas Nível 1

\begin{tabular}{|c|c|c|c|c|}
\hline \multicolumn{2}{|l|}{ Variável } & $\mathrm{ROA}$ & $\mathrm{ROE}$ & $\begin{array}{l}\mathrm{Q} \text { de } \\
\text { Tobin }\end{array}$ \\
\hline \multirow{2}{*}{ Constante } & Coeficiente & 0,096 & $-1,099$ & 1,06 \\
\hline & Sig. & 0,556 & 0,341 & $0,029^{*}$ \\
\hline \multirow{2}{*}{$\begin{array}{l}\text { Independência do Conselho de Ad- } \\
\text { ministração }\end{array}$} & Coeficiente & 0,000 & 0,004 & $-1,47$ \\
\hline & Sig. & 0,459 & 0,276 & 0,354 \\
\hline \multirow{2}{*}{ Dualidade do Diretor } & Coeficiente & $-0,004$ & 0,098 & $-2,37$ \\
\hline & Sig. & 0,862 & 0,511 & 0,705 \\
\hline \multirow{2}{*}{ Auditoria Big Four } & Coeficiente & 0,028 & 0,056 & $-6,60$ \\
\hline & Sig. & 0,590 & 0,878 & 0,668 \\
\hline \multirow{2}{*}{ Comitê de Auditoria } & Coeficiente & 0,046 & 0,117 & $-8,52$ \\
\hline & Sig. & $0,036^{*}$ & 0,449 & 0,896 \\
\hline \multirow{2}{*}{$\begin{array}{l}\text { Tamanho do Conselho de Adminis- } \\
\text { tração }\end{array}$} & Coeficiente & $-0,086$ & $-0,750$ & 2,94 \\
\hline & Sig. & 0,406 & 0,309 & 0,342 \\
\hline \multirow{2}{*}{$\begin{array}{l}\text { Expertise do Conselho de Adminis- } \\
\text { tração }\end{array}$} & Coeficiente & 0,001 & 0,000 & 3,89 \\
\hline & Sig. & 0,531 & 0,965 & 0,224 \\
\hline \multirow{2}{*}{$\begin{array}{l}\text { Gênero do Conselho de Adminis- } \\
\text { tração }\end{array}$} & Coeficiente & 0,000 & 0,006 & 2,62 \\
\hline & Sig. & 0,859 & 0,593 & 0,956 \\
\hline \multirow{2}{*}{ Tamanho da Empresa } & Coeficiente & $-0,006$ & 0,165 & $-1,57$ \\
\hline & Sig. & 0,736 & 0,223 & $0,007^{* *}$ \\
\hline \multicolumn{2}{|l|}{$\mathrm{R}^{2}$} & 0,584 & 0,197 & 0,315 \\
\hline \multicolumn{2}{|l|}{$\mathrm{R}^{2}$ Ajustado } & 0,508 & 0,179 & 0,293 \\
\hline \multicolumn{2}{|l|}{ Pesarán-Pesarán } & 0,757 & 0,941 & 0,416 \\
\hline \multicolumn{2}{|l|}{ Durbin-Watson } & 2,091 & 2,062 & 2,133 \\
\hline \multicolumn{2}{|l|}{ ANOVA } & 0,050 & 0,415 & 0,001 \\
\hline
\end{tabular}

* Significância no nível de 5\%. ** Significância no nível de 1\%.

Fonte: Dados da pesquisa.

Em relação as variáveis referentes aos mecanismos de governança corporativa, apenas o "comitê de auditoria" apresentou-se positivamente relacionado com o ROA, resultado que difere dos achados de Hsu e Petchsakulwong (2010), pois encontraram evidências de uma relação negativa entre o comitê de auditoria e o desempenho empresarial. Este resultado sugere que as empresas 
listadas no nível 1, que possuem comitê de auditoria, apresentam melhor desempenho quanto ao retorno dos seus ativos. Assim, quanto mais desenvolvido for o comitê de auditoria, melhor tende a ser a eficiência operacional destas empresas, pois conforme o IBGC (2009), este comitê possui como função uma supervisão ativa, contribuindo para que os controles internos funcionem de forma efetiva, o que impacta positivamente no desempenho. Além disso, Hsu e Petchsakulwong (2010) abordam que um comitê de auditoria fornece um monitoramento rigoroso nas empresas quando constituído por um maior número de membros.

Nesse sentido, quanto as hipóteses de pesquisa, para as empresas pertencentes ao nível 1, apenas a H4 pode ser confirmada: $a$ presença de um comitê de auditoria aumenta o desempenho empresarial, mensurado pelo ROA. Portanto, não foram encontradas relações significativas com as demais variáveis de mecanismos de governança corporativa (independência do conselho de administração, dualidade do diretor, auditoria big four, tamanho, expertise e gênero do conselho de administração) e variável de controle (tamanho da empresa). Conclui-se para com a análise das empresas do nível 1 da B3 que entre os mecanismos de governança corporativa, apenas o comitê de auditoria possui relação significativa com o desempenho empresarial.

\subsection{Resultados da regressão: empresas nível 2}

Na Tabela 6 apresentam-se os resultados para esta amostra de empresas do Nível 2.

No que tange ao ROA, o mecanismo de governança corporativa "expertise do conselho de administração" apresentou relação positiva com este desempenho. Este resultado revela que a qualificação profissional dos conselheiros impacta positivamente no retorno sobre os ativos. Deste modo, quanto mais os conselheiros possuem qualificação profissional voltada para a área de finanças e contabilidade, melhor é o resultado auferido pelas empresas do nível 2 quanto a variável ROA. Tais resultados corroboram com os estudos desenvolvidos por Ujunwa (2012) e Dani et al. (2017), pois também encontraram uma relação positiva entre a expertise do conselho e o ROA. Por outro lado, os achados de Ehikiova (2009) se diferem dos encontrados na presente pesquisa, pois evidenciaram uma relação sem significância entre tais variáveis. 
Tabela 6 - Resultados da regressão - Empresas Nível 2

\begin{tabular}{|c|c|c|c|c|}
\hline \multicolumn{2}{|c|}{ Variável } & $\mathrm{ROA}$ & ROE & Q de Tobin \\
\hline \multirow{2}{*}{ Constante } & Coeficiente & $-0,179$ & $-0,286$ & 9,28 \\
\hline & Sig. & 0,540 & 0,948 & $0,000^{*}$ \\
\hline \multirow{2}{*}{$\begin{array}{l}\text { Independência do Conse- } \\
\text { lho de Administração }\end{array}$} & Coeficiente & $-0,001$ & $-0,002$ & $-3,51$ \\
\hline & Sig. & 0,126 & 0,885 & 0,424 \\
\hline \multirow{2}{*}{ Dualidade do Diretor } & Coeficiente & $-0,015$ & 0,314 & $-1,21$ \\
\hline & Sig. & 0,614 & 0,488 & 0,933 \\
\hline \multirow{2}{*}{ Auditoria Big Four } & Coeficiente & 1,15 & 2,10 & 2,45 \\
\hline & Sig. & 0,560 & 0,123 & 0,620 \\
\hline \multirow{2}{*}{ Comitê de Auditoria } & Coeficiente & $-0,031$ & 0,369 & 3,11 \\
\hline & Sig. & 0,285 & 0,390 & 0,820 \\
\hline \multirow{2}{*}{$\begin{array}{l}\text { Tamanho do Conselho de } \\
\text { Administração }\end{array}$} & Coeficiente & 0,086 & 1,496 & 3,61 \\
\hline & Sig. & 0,501 & 0,438 & 0,557 \\
\hline \multirow{2}{*}{$\begin{array}{l}\text { Expertise do Conselho } \\
\text { de Administração }\end{array}$} & Coeficiente & 0,002 & 0,032 & 3,92 \\
\hline & Sig. & $0,045^{*}$ & $0,050^{*}$ & 0,504 \\
\hline \multirow{2}{*}{$\begin{array}{l}\text { Gênero do Conselho de } \\
\text { Administração }\end{array}$} & Coeficiente & 0,001 & $-0,001$ & $-1,06$ \\
\hline & Sig. & 0,704 & 0,983 & 0,478 \\
\hline \multirow{2}{*}{ Tamanho da Empresa } & Coeficiente & 0,023 & $-0,322$ & $-1,00$ \\
\hline & Sig. & 0,486 & 0,507 & $0,000^{* *}$ \\
\hline \multicolumn{2}{|l|}{$\mathrm{R}^{2}$} & 0,569 & 0,309 & 0,815 \\
\hline \multicolumn{2}{|l|}{$\mathrm{R}^{2}$ Ajustado } & 0,523 & 0,287 & 0,664 \\
\hline \multicolumn{2}{|l|}{ Pesarán-Pesarán } & 0,504 & 0,599 & 0,410 \\
\hline \multicolumn{2}{|l|}{ Durbin-Watson } & 1,677 & 2,001 & 1,615 \\
\hline \multicolumn{2}{|l|}{ ANOVA } & 0,002 & 0,005 & 0,000 \\
\hline
\end{tabular}

* Significância no nível de 5\%. ** Significância no nível de 1\%.

Fonte: Dados da pesquisa.

Estas evidências, conforme Ehikioya (2009), indicam que as empresas que possuem conselheiros no conselho de administração com as habilidades necessárias e que visam, bem como, incentivam o aprendizado, apresentam desempenho superior. Portanto, é de suma importância que as empresas tenham políticas que garantem a consideração da qualificação profissional dos membros do conselho antes da sua nomeação, visto que este fato pode acarretar impactos no desempenho (EHIKIOYA, 2009). Além disso, há a necessidade 
de treinamentos e qualificações contínuas com vistas a garantir um desempenho eficiente de suas responsabilidades e reflexos positivos no desempenho das empresas (EHIKIOYA, 2009). Este achado positivo da expertise do conselho e o desempenho avaliado pelo ROA, implica que a qualificação educacional dota os diretores de conhecimento, experiência e habilidades gerenciais e administrativas para a condução coerente dos negócios e com a intenção de melhorar o desempenho (AKPAN; AMRAN, 2014). Além disso, este achado para as empresas do Nível 2, possibilitou confirmar apenas a hipótese H6 do estudo, que versa que: a presença de executivos no conselho de administração com expertise financeira e administrativa aumenta o desempenho empresarial, avaliado pelo Retorno sobre os Ativos (ROA).

A variável de controle "tamanho da empresa" apresentou-se negativamente relacionada ao $Q$ de Tobin, o que revela que empresas menores pertencentes ao nível 2 de governança corporativa da B3 apresentam menor desempenho de mercado, mensurado pelo $Q$ de Tobin. Por fim, outras variáveis referentes aos mecanismos de governança corporativa não apresentaram relação com o ROA e $Q$ de Tobin. Para tanto, entre os mecanismos de governança corporativa analisados das empresas do nível 2, apenas a variável expertise do conselho de administração possui relação significativa com o desempenho empresarial avaliado pelo ROA.

\subsection{Resultados da regressão: empresas do novo mercado}

Nesta seção apresentam-se os resultados para as empresas listadas no novo mercado.

O poder explicativo de cada mecanismo de governança corporativa analisado indica que a "independência do conselho de administração" está negativamente relacionada com o ROA. Este achado revela que a participação de membros externos à empresa no conselho de administração, reduz o desempenho econômico-financeiro (ROA), das empresas do novo mercado, visto a relação encontrada ser negativa. Tais resultados corroboram com os estudos desenvolvidos por Adams e Ferreira (2009) e Dani et al. (2017), pois também constataram uma relação negativa entre a independência do conselho de administração e o ROA. Deste modo, a proporção de conselheiros independentes mostrou influência negativa sobre o desempenho empresarial medido pelo ROA, não se confirmando a hipótese H4, que conjecturava o oposto. 
Tabela 7 - Resultados da regressão - Empresas Novo Mercado

\begin{tabular}{|c|c|c|c|c|}
\hline \multicolumn{2}{|l|}{ Variável } & $\mathrm{ROA}$ & $\mathrm{ROE}$ & Q de Tobin \\
\hline \multirow{2}{*}{ Constante } & Coeficiente & 7,037 & $-0,259$ & 5,56 \\
\hline & Sig. & 0,557 & 0,914 & $0,002^{* *}$ \\
\hline \multirow{2}{*}{$\begin{array}{l}\text { Independência do Conselho de } \\
\text { Administração }\end{array}$} & Coeficiente & $-5,001$ & 0,006 & 7,48 \\
\hline & Sig. & $0,000^{*}$ & 0,336 & 0,104 \\
\hline \multirow{2}{*}{ Dualidade do Diretor } & Coeficiente & 1,013 & 0,156 & $-1,11$ \\
\hline & Sig. & 0,085 & 0,572 & 0,588 \\
\hline \multirow{2}{*}{ Auditoria Big Four } & Coeficiente & 6,084 & 0,659 & 8,67 \\
\hline & Sig. & $0,000^{*}$ & 0,378 & 0,118 \\
\hline \multirow{2}{*}{ Comitê de Auditoria } & Coeficiente & 4,000 & $-0,165$ & 4,28 \\
\hline & Sig. & 0,979 & 0,555 & $0,039^{*}$ \\
\hline \multirow{2}{*}{$\begin{array}{l}\text { Tamanho do Conselho de Admi- } \\
\text { nistração }\end{array}$} & Coeficiente & 8,055 & $-1,156$ & $-1,02$ \\
\hline & Sig. & $0,027^{*}$ & 0,220 & 0,145 \\
\hline \multirow{2}{*}{$\begin{array}{l}\text { Expertise do Conselho de Admi- } \\
\text { nistração }\end{array}$} & Coeficiente & 5,000 & 0,002 & 2,37 \\
\hline & Sig. & $0,050^{*}$ & 0,830 & $0,000^{* *}$ \\
\hline \multirow{2}{*}{$\begin{array}{l}\text { Gênero do Conselho de Adminis- } \\
\text { tração }\end{array}$} & Coeficiente & $-14,000$ & $-0,011$ & 8,06 \\
\hline & Sig. & 0,297 & 0,499 & 0,486 \\
\hline \multirow{2}{*}{ Tamanho da Empresa } & Coeficiente & 12,013 & 0,093 & $-7,60$ \\
\hline & Sig. & $0,019^{*}$ & 0,728 & $0,000^{* *}$ \\
\hline \multicolumn{2}{|l|}{$\overline{R^{2}}$} & 0,610 & 0,104 & 0,637 \\
\hline \multicolumn{2}{|l|}{$\overline{\mathrm{R}^{2} \text { Ajustado }}$} & 0,585 & 0,011 & 0,589 \\
\hline \multicolumn{2}{|l|}{ Pesarán-Pesarán } & 0,515 & 0,781 & 0,462 \\
\hline \multicolumn{2}{|l|}{ Durbin-Watson } & 1,939 & 2,018 & 1,971 \\
\hline \multicolumn{2}{|l|}{ ANOVA } & 0,000 & 0,506 & 0,000 \\
\hline
\end{tabular}

* Significância no nível de 5\%. ** Significância no nível de 1\%.

Fonte: Dados da pesquisa.

Este resultado se contrapõem aos argumentos da Teoria da Agência (JENSEN; MECKLING, 1976), pois esta teoria aborda que conselhos de administração que possuem uma quantidade maior de membros independentes, provavelmente serão monitores mais eficazes das práticas realizadas nas empresas pelos conselheiros não independentes e demais membros da empresa, com vistas a diminuição dos conflitos de agência (WAHBA, 2015). Também não 
corrobora com os argumentos de Hsu e Petchsakulwong (2010), pois os autores sugerem que a independência do conselho aprimora a eficiência de uma empresa. Portanto, a independência do conselho nas empresas do novo mercado, pode ser importante para com o monitoramento das empresas com vistas a evitar fraudes (HSU; PETCHSAKULWONG, 2010) e menos oportuna no que tange ao atingimento de desempenho superior. Conforme Gaur, Bathula e Singh (2015) a independência do conselho de administração geralmente não apresenta impactos diretos no desempenho, mas sim, no desempenho das tarefas no conselho, visto que a presença de membros independentes no conselho, tende a aumentar as chances de conflitos de agência, o que ocasiona tomada de decisão menos eficiente e apresenta reflexos no desempenho.

Quanto a variável "auditoria big four", Dani et al. (2017) sugeriram a realização de novos estudos sobre a relação das características do comitê de auditoria com o desempenho empresarial. Deste modo, foram testadas as variáveis: Auditoria por Big Four e a existência de Comitê de auditoria. Os resultados revelaram que as empresas pertencentes ao novo mercado e auditadas por uma empresa de auditoria considerada Big Four, apresentam impactos positivos no ROA. Além disso, a existência de um "comitê de auditoria" apresentou reflexos positivos no $Q$ de Tobin. Estes achados reforçam a necessidade de as empresas terem um comitê de auditoria e contratarem empresas de auditoria Big Four, visto os impactos positivos destas variáveis no desempenho econômico-financeiro (ROA) e de mercado $Q$ de Tobin. Tais resultados ainda permitiram aceitar a $\mathrm{H} 3$ para o desempenho empresarial mensurado pelo ROA: empresas auditadas por Big Four aumentam o desempenho empresarial, e H4 para o desempenho de mercado ( $Q$ de Tobin): a presença de um comitê de auditoria aumenta o desempenho empresarial.

A variável "tamanho do conselho" apresentou relação positiva com o ROA, o que revela que um conselho maior, com mais números de membros é benéfico para a empresa em termos de captação de recursos e contribuições dos conselheiros no que tange suas habilidades, experiências e conhecimentos para com o desempenho financeiro da empresa (AKPAN; AMRAN, 2014). Denota-se, portanto, que empresas que possuem um número baixo de 
conselheiros apresentam menores probabilidades de exercer com eficiência as suas atribuições de trabalho (monitorar as decisões dos administradores e proteger as partes interessadas) (ANDRADE et al., 2009). Fatos estes que tendem a impactar no desempenho.

Para tanto, o tamanho do conselho pode ser um fator relevante para o monitoramento das decisões dos gestores, direcionando as suas decisões para estratégias que maximizam a riqueza dos acionistas e contribuem para com um desempenho superior (ANDRADE et al., 2009). Assim, o tamanho ideal do conselho tende a ter um impacto positivo no desempenho (EHIKIOYA, 2009). Este resultado positivo entre o tamanho do conselho e o ROA corrobora com os achados de Ehikiova (2009), Dani et al. (2017) e Costa e Martins (2019). Por outro lado, é um resultado contrário ao esperado, fato este que não permitiu aceitar a H5 do estudo: a maior proporção de executivos no conselho de administração reduz o desempenho empresarial, pois esperava-se uma relação negativa entre o tamanho do conselho e o desempenho empresarial.

No que tange a variável "expertise do conselho de administração", que se refere a qualificação educacional e profissional dos membros do conselho (DANI et al., 2017), a relação foi positiva com o ROA e $Q$ de Tobin, e assim, confirma a H6 do estudo: a presença de executivos no conselho de administração com expertise financeira e administrativa aumenta o desempenho empresarial. Este resultado revela que a relação entre o número de membros com graduação ou pós-graduação em Ciências Contábeis, Administração ou Economia e o número total de conselheiros, impacta positivamente o desempenho econômico-financeiro e o desempenho de mercado. Deste modo, os investidores tendem a valorizar as ações de empresas em função dessa característica "expertise" do conselho, visto os seus reflexos positivos no desempenho. Além disso, as expectativas de valor criadas pelos investidores são influenciadas por maior percentual de conselheiros com expertise na área contábil, administração e economia. Tais achados corroboram com os estudos de Ujunwa (2012) e Dani et al. (2017) para a variável ROA. Por outro lado, se diferem dos resultados encontrados por Ehikiova (2009) para o desempenho de mercado, pois o autor não encontrou significância estatística para a relação entre a expertise do conselho e o $Q$ de Tobin. 
Conforme os resultados apresentados na Tabela 7 denota-se que as variáveis dualidade do diretor, comitê de auditoria e gênero do conselho de administração não apresentaram impactos no desempenho medido pelo ROA para as empresas do novo mercado. Em relação ao $Q$ de Tobin as seguintes variáveis relacionadas a governança corporativa não conseguiram explicar o desempenho de mercado das empresas do novo mercado: independência do conselho, dualidade do diretor, auditoria Big Four, tamanho e gênero do conselho de administração.

No que diz respeito a variável de controle, os resultados revelaram que o "tamanho da empresa" se relacionou positivamente com o ROA e negativamente com o $Q$ de Tobin. Este resultado indica que empresas maiores e consolidadas no mercado tendem a apresentar melhores expectativas dos investidores em relação a valorização de suas ações (ANDRADE et al., 2009), bem como, o retorno sobre os investimentos auferidos no ativo da empresa. O resultado para a variável ROA se assemelha aos achados de Andrade et al. (2009). Contudo, se difere para com os resultados do $Q$ de Tobin, visto que os autores encontraram uma relação positiva entre o tamanho da empresa e o valor de mercado. Também se difere do estudo de Wahba (2015), pois o tamanho da empresa não se apresentou relacionado com o $Q$ de Tobin.

A partir dos resultados supracitados denota-se que a relação entre os mecanismos de governança corporativa e o desempenho empresarial se difere entre as amostras analisadas, o que revela que diferentes mecanismos funcionam em determinadas empresas como promotores do desempenho. No geral, os achados revelaram que o mecanismo de governança corporativa "expertise do conselho de administração" é um fator chave nas organizações pertencentes ao nível 2 e novo mercado, para alavancar o desempenho econômico-financeiro e de mercado. Portanto, as empresas devem prestar a atenção para com a expertise dos membros do conselho, visto que este mecanismo tende a assegurar um desempenho empresarial superior. No entanto, "os estudos empíricos sobre esse tema geralmente divergem em seus resultados, e não é possível inferir de maneira mais geral o impacto que essa prática pode ter nas organizações" (COSTA; MARTINS, 2019, p. 414). 


\subsection{Discussão e implicação dos resultados}

Uma das "principais questões quando se trata de governança corporativa é a Teoria da Agência e os conflitos que podem existir quando não há separação de propriedade e controle" (COSTA; MARTINS, 2019, p. 414). Nesse sentido, a forma como as empresas são gerenciadas e a estrutura de gestão, são importantes fatores, pois apresentam um impacto direto na tomada de decisões estratégicas e na direção que a empresa irá assumir tanto no curto, quanto no longo prazo (COSTA; MARTINS, 2019, p. 414). Logo, tais fatores tendem a impactar também no desempenho empresarial. Denota-se conforme a Teoria da Agência, que o conselho de administração é um mecanismo de controle interno, que lida com os conflitos de interesse entre gerentes e acionistas, com vistas a trazer ambos os interesses em congruência (JENSEN; MECKLING, 1976; UJUNWA, 2012), e tais interesses tendem a impactar o desempenho empresarial. Portanto, o conselho de administração desempenha um papel importante para as empresas e para a governança corporativa destas, pois "podem trazer inúmeros benefícios para o cumprimento das estratégias organizacionais, se a composição do conselho e o desempenho dos membros do conselho forem eficazes" (COSTA; MARTINS, 2019, p. 406).

Esta abordagem de Costa e Martins (2019), pode ser confirmada a partir dos achados encontrados, pois dentre os mecanismos de governança corporativa, a expertise do conselho de administração apresentou destaque, o que sugere que a qualificação educativa e profissional dos membros do conselho auxilia na tomada de decisão precisa e no desenvolvimento de estratégias eficazes para a empresa melhorar o seu desempenho a cada ano. De acordo com Gaur, Bathula e Singh (2015), a qualificação profissional dos conselheiros é um indicativo da competência do conselho de administração e pode auxiliar na captação de recursos, visto que qualificações adequadas, altos níveis de capacidade intelectual e experiência profissional tendem a apresentar reflexos positivos para as empresas. Deste modo, a estrutura de governança corporativa das empresas, como estrutura acionária, composição do conselho de administração, tamanho do conselho, dívida, dualidade do CEO, entre outros mecanismos de governança, possuem influência no desempenho empresarial (EHIKIOYA, 2009). 
Nesse sentido, a adoção de boas práticas de governança corporativa nas empresas tende a proporcionar a redução do custo de capital, risco para as partes interessadas, além de melhorar a qualidade e a transparência das informações divulgadas. Para tanto, tais práticas tendem a impactar positivamente, direta ou indiretamente, o resultado da empresa, o que gera condições para o aumento da riqueza gerada para os acionistas (FERNANDES; DIAS; CUNHA, 2010).

Diante do contexto supracitado e a partir dos resultados encontrados para um mercado emergente, como é o caso do Brasil, nota-se que a relação entre governança corporativa e desempenho empresarial pode ser resumida na abordagem de Claessens e Yurtoglu (2013, p. 1), pois elencam que "uma melhor governança corporativa beneficia as empresas por meio de maior acesso a financiamento, menor custo de capital, melhor desempenho e tratamento mais favorável a todas as partes interessadas".

Esta pesquisa apresenta implicações importantes para os profissionais das empresas listadas nos níveis de governança corporativa analisados, pois os resultados sobre os principais mecanismos de governança que visam melhorar o desempenho empresarial, podem ser tema de avaliações no conselho de administração. O presente estudo também possui relevância prática no tange ao processo de seleção dos membros do conselho de administração, pois destaca a importância da expertise dos profissionais que irão atuar no conselho.

Para os investidores esta pesquisa apresenta indícios de que os mecanismos de governança corporativa são relevantes para o alcance de melhor desempenho empresarial, o que consequentemente maximiza os retornos aos acionistas e demais partes interessadas. Portanto, a análise dos mecanismos de governança corporativa deve ser levada em consideração no momento do investimento de recursos nas empresas. No que tange aos formuladores de políticas públicas, esta pesquisa apresenta implicações no sentido destes órgãos estimularem cada vez mais a aderência das empresas a um ambiente apropriado de governança corporativa.

\section{Considerações finais}

Esta pesquisa teve por objetivo analisar a relação entre os mecanismos de governança corporativa e o desempenho empresarial de 
empresas brasileiras listadas nos níveis de governança corporativa Nível 1, Nível 2 e Novo Mercado da B3. Quanto aos três modelos (ROA, ROE e $Q$ de Tobin) analisados para cada amostra de empresas, os resultados revelaram um baixo coeficiente de determinação para a rentabilidade do patrimônio líquido (ROE), nas três amostras, o que não possibilitou a análise das variáveis de mecanismos de governança corporativa no ROE. Denota-se ainda, que nas empresas do nível 1, apenas o efeito dos mecanismos de governança na variável ROA foram considerados, visto também o baixo coeficiente de determinação dos modelos ROE e $Q$ de Tobin.

Nesse sentido, para a amostra de empresas do Nível 1, os resultados revelaram que dentre os mecanismos de governança corporativa analisados, apenas o comitê de auditoria relacionou-se positivamente com o retorno sobre os ativos. Este resultado confirma a abordagem do código de melhores práticas de governança corporativa, disponibilizado pelo IBCG (2009), pois aborda que as empresas que possuem um comitê de auditoria com uma supervisão ativa, passam a assegurar que os sistemas de controles internos funcionam de forma efetiva, o que apresenta reflexos benéficos no desempenho das empresas.

Os resultados indicaram uma relação positiva entre a expertise do conselho de administração e o desempenho mensurado pelo ROA, para a amostra de empresas pertencentes ao nível 2. Estes resultados revelam que os membros do conselho que possuem qualificação na área de finanças, contabilidade e áreas afins, apresentam conhecimento sobre a gestão das empresas, experiência profissional e melhores competências gerenciais para subsidiar a tomada de decisão (AKPAN; AMRAN, 2014; GAUR; BATHULA; SINGH, 2015). Contudo, quanto ao desempenho de mercado nenhuma das variáveis dos mecanismos de governança corporativa apresentaram efeitos neste desempenho, apenas a variável de controle (tamanho da empresa), o que demonstra que os mecanismos de governança corporativa adotados pelas empresas do nível 2, não são suficientes para explicar o desempenho de mercado destas empresas. $\mathrm{O}$ que sugere a introdução de outras variáveis no modelo que possam auxiliar na explicação do desempenho empresarial medido pelo $Q$ de Tobin. Entretanto, este resultado pode ser explicado também 
pelo tamanho da amostra de empresas pertencentes ao nível 2 de governança corporativa.

A análise das empresas listadas no novo mercado, revelou uma relação negativa entre a independência do conselho de administração e o desempenho econômico-financeiro, avaliado pelo ROA. Tais resultados indicam que uma maior proporção de conselheiros independentes no conselho de administração apresenta reflexos negativos no ROA. Este fato pode ocorrer, devido ao conflito de interesses entre os conselheiros internos e os externos, o que consequentemente torna a tomada de decisões menos eficiente (GAUR; BATHULA; SINGH, 2015) e ocasiona menor desempenho do retorno sobre os ativos. Por outro lado, os mecanismos de governança corporativa: auditoria Big Four, tamanho e expertise do conselho de administração apresentaram relação positiva com o ROA. Deste modo, nota-se que quanto maior for o tamanho do conselho, melhor tende a ser o desempenho econômico-financeiro (AKPAN; AMRAN, 2014; WAHBA, 2015) das empresas do novo mercado. Para este resultado favorável, também se faz necessário que tais empresas sejam auditadas por uma Big Four e possuem profissionais com habilidades e experiências na área de finanças e gestão, visto que tais qualificações profissionais apresentaram relação positiva com o retorno sobre os ativos.

Ainda para as empresas do novo mercado, os resultados indicaram que o comitê de auditoria e a expertise do conselho de administração se relacionam positivamente com o $Q$ de Tobin. Estes resultados revelam que a expertise do conselho de administração apresenta efeitos positivos tanto no desempenho econômico-financeiro (ROA) quanto no desempenho de mercado ( $Q$ de Tobin). Deste modo, a qualificação profissional, a experiência dos conselheiros é um mecanismo de governança corporativa que assegura o alcance de melhor desempenho empresarial das empresas listadas no novo mercado da B3. Além disso, os resultados revelam a importância do comitê de auditoria nas empresas para o alcance de desempenho superior.

Conclui-se diante dos resultados supracitados que as empresas listadas nos níveis de governança corporativa nível 1, nível 2 e novo mercado, possuem no geral os mecanismos de governança corporativa aprimorados, visto as exigências para estarem listadas nestes níveis da B3. No entanto, nas empresas do nível 1, tais meca- 
nismos não asseguram de certa forma desempenho superior, visto que apenas o comitê de auditoria relacionou-se com a variável ROA. Portanto, esta tendência de as empresas se adequarem ao código de governança corporativa, demonstra interesse em continuar listadas nestes níveis e de constituir, bem como, consolidar um ambiente de proteção legal aos investidores (ANDRADE et al., 2009). Tais aspetos tendem a contribuir para com o desempenho econômico-financeiro e de mercado.

Como limitações destaca-se o fato de a análise ser especificamente de empresas brasileiras, não financeiras listadas no nível 1, nível 2 e novo mercado da B3, o que impossibilita a generalização dos resultados para todas as empresas listadas na B3. Outra limitação refere-se as variáveis utilizadas para mensurar o desempenho empresarial, os mecanismos de governança corporativa e a variável de controle, pois outras variáveis também poderiam ser utilizadas para explicar a relação proposta. Apesar destas limitações, os procedimentos adotados para o desenvolvimento da pesquisa não invalidam sua realização.

A partir da realização deste estudo, denota-se a oportunidade para a realização de novos estudos sobre a temática analisada. Recomenda-se para futuras pesquisas a utilização de outros indicadores de desempenho empresarial e de governança corporativa, e a análise de outras empresas listadas na B3. Outra oportunidade refere-se à utilização de uma abordagem qualitativa, pois as características do conselho de administração, como por exemplo, a independência e a expertise, podem ser melhor explicadas a partir de uma abordagem qualitativa, levando-se em consideração o perfil geral dos membros do conselho. Conforme Wahba (2015, p. 34-35), "examinar como a relação entre os mecanismos de governança corporativa e o desempenho financeiro varia com o ciclo de vida de uma empresa é outra área promissora para pesquisas futuras", pois "os parâmetros de governança corporativa podem estar relacionados a limites estratégicos no ciclo de vida das empresas" (WAHBA, 2015, p. 35).

\section{REFERÊNCIAS}

ADAMS, R. B.; FERREIRA, D. Women in the boardroom and their impact on governance and performance. Journal of Financial Economics, v. 94, n. 2, p. 291-309, 2009. 
AKPAN, E. O.; AMRAN, N. A. Board characteristics and company performance: Evidence from Nigeria. Journal of Finance and Accounting, v. 2, n. 3, p. 81-89, 2014.

AMARAL-BAPTISTA, M. A.; KLOTZE, M. C.; MELO, M. A. C. Ceo duality and firm performance in Brazil: evidence from 2008. Revista Pensamento Contemporâneo em Administração, v. 5, n. 1, p. 24-37, 2011.

ANDRADE, L. P. de; SALAZAR, G. T.; CALEGÁRIO, C. L. L.; SILVA, S. S. Governança corporativa: uma análise da relação do conselho de administração como valor de mercado e desempenho das empresas brasileiras. Revista de Administração Mackenzie, v. 10, n. 4, p. 4-31, 2009.

ASSAF NETO, A. Finanças corporativas e valor. 6. ed. São Paulo: Atlas, 2012.

CAIXE, D. F.; KRAUTER, E. A Influência da Estrutura de Propriedade e Controle sobre o Valor de Mercado Corporativo no Brasil. Revista Contabilidade \& Finanças, v. 24, n. 62, p. 142-253, 2013.

CALDAS, C. B.; TAMBOSI FILHO, E.; VIEIRA, A. M. Governança Corporativa e Sustentabilidade: uma relação necessária. Revista UNIABEU, v. 7, p. 353-369, 2014.

CHEN, T.; CHEN, C. B.; PENG, S.Y. Firm operation performance analysis using data envelopment analysis and balanced scorecard: a case study of a credit cooperative bank. International Journal of Productivity and Performance Management, v. 57, n. 7, p. 523-539, 2008.

CLAESSENS, S.; YUTORGLU, B. B. Corporate governance in emerging markets: A survey. Emerging Markets Review, v. 15, n. 1, p. 1-33, 2013.

CORREIA, L. F.; AMARAL, H. F.; LOUVET, P. Determinantes da eficiência de conselhos de administração de empresas negociadas na BM\&FBovespa. Revista de Contabilidade e Organizações, v. 8, n. 21, p. 46-57, 2014.

COMISSÃO DE VALORES IMOBILIÁRIOS - CVM. Recomendações da CVM sobre governança corporativa. 2002. Disponível em: <http://www.cvm.gov.br>. Acesso em: 18 set. 2019.

COSTA, Y. C. L. da; MARTINS, O. S. CEO duality and corporate performance: evidence in the brazilian capital market. Revista de Administração da UFSM, v. 12, n. 3, p. 403-417, 2019.

DARMADI, S. Board diversity and firm performance: the Indonesian evidence. Corporate Ownership and Control Journal, v. 9, n. 1, p. 524-539, 2011.

DANI, A. C.; KAVESKI, I. D. S.; SANTOS, C. A. dos.; LEITE, A. P. P.; CUNHA, P. R. da. Características do conselho de administração e o desempenho empresarial das empresas listadas no novo mercado. Revista de Gestão, Finanças e Contabilidade, v. 7, n. 1, p. 29-47, 2017.

EDGLEY, C.; SHARMA, N.; ANDERSON-GOUGH, F. Diversity and professionalism in the Big Four Firms: Expectation, celebration and weapon in the battle for talent. Critical Perspectives on Accounting, v. 35, n. 1, p. 13-34, 2016.

EHIKIOVA, B. I. Corporate governance structure and firm performance in developing economies: evidence from Nigeria. Corporate Governance: The International Journal of Business in Society, v. 9, n. 3, p. 231-243, 2009. 
FAMÁ, R.; BARROS, L. A. B. de C. $Q$ de Tobin e seu uso em finanças: aspectos metodológicos e conceituais. Caderno de Pesquisas em Administração, v. 7, n. 4, p. 27-43, 2000.

FÁVERO, L. P.; BELFIORE, P.; SILVA, F. L. da.; CHAN, B. L. Análise de dados: modelagem multivariada para tomada de decisão. São Paulo: Campus, 2009.

FERNANDES, N. A. C.; DIAS, W. de O.; CUNHA, J. V. A da. Governança corporativa no contexto brasileiro: um estudo do desempenho das companhias listadas nos níveis da BM\&FBOVESPA. Revista Organizações em Contexto, v. 6, n. 11, p. 22-44, 2010.

GASPARETTO, V. O papel da contabilidade no provimento de informações para a avaliação do desempenho empresarial. Revista Contemporânea de Contabilidade, v. 1, n. 2, p. 109122, 2004.

GAUR, S. S.; BATHULA, H.; SINGH, D. Ownership concentration, board characteristics and firm performance: a contingency framework. Management Decision, v. 53, n. 5, p. 911-931, 2015.

GE, W.; LIU, M. Corporate social responsibility and the cost of corporate bonds. Journal of Accounting and Public Policy, v. 34, n. 6, p. 597-624, 2015.

GUJARATI, D. N.; PORTER, D. C. Econometria básica. 5. ed. Porto Alegre: Bookman, 2011.

HAIR J. F.; ANDERSON, R. E.; TATHAM, R. L.; BLACK W. C. Análise Multivariada de Dados. 5. ed. Porto Alegre: Bookman. 2005.

HSU, W.Y.; PETCHSAKULWONG, P. The impact of corporate governance on the efficiency performance of the Thai Non-Life insurance industry. Genoveva Papers on Risk and Insurance: Issues and Practice, v. 35, n. 1, p. 28-49, 2010.

INSTITUTO DE GOVERNANÇA CORPORATIVA - IBGC. Governança corporativa. 2004. Disponível em: <http://www.ibgc.org.br>. Acesso em: 18 set. 2019.

Código das melhores práticas de governança corporativa. 4. ed. São Paulo: IBGC, 2009.

JENSEN, M.; MECKLING, W. Theory of the firm: managerial behavior, agency costs and ownership structure. Journal of Financial Economics, v. 3, n. 4, p. 305-360,1976.

MALACRIDA, M. J.; YAMAMOTO, M. M. Governança corporativa: nível de evidenciação das informações e sua relação com a volatilidade das ações do Ibovespa. Revista Contabilidade \& Finanças, v. 17, n. 1, p. 65-79, 2006.

MARTINS, H. C. Papéis dos conselhos de administração: perspectivas teóricas. Revista de Administração FEAD, v. 2, n. 1, p. 97-109, 2005a.

MAYORAL, J. M.; SEGURA, A. S. Un estudio empírico de los honorarios del auditor. Cuadernos de Economía y Dirección de la Empresa, v. 10, n. 32, p. 81-109, 2007.

MOSCU, R. G. Does CEO Duality Really Affect Corporate Performance? International Journal of Academic Research in Economics and Management Sciences, v. 2, n. 1, p. 156-166, 2013.

O'SULLIVAN, N. Why do CEOs hold non-executive directorships? An analysis of the role of governance and ownership. Management Decision, v. 47, n. 5, p. 760-777, 2009. 
OWHOSO, V.; WEICKGENANNT, A. Auditors' self-perceived abilities in conducting domain audits. Critical Perspectives on Accounting, v. 20, n. 1, p. 3-21, 2009.

PELEIAS, I. R; SEGRETI, J. B.; COSTA, C. A. Comitê de auditoria ou órgãos equivalentes no contexto da Lei Sarbanes-Oxley: estudo da percepção dos gestores de empresas brasileiras emitentes de American Depositary Receipts - ADRs. Contabilidade Vista \& Revista, v. 20, n. 1, p. 41-65, 2009.

PEREZ, M. M.; FAMÁ, R. Métodos de avaliação de empresas e o balanço de determinação. Caderno de Pesquisa em Administração, v. 10, n. 4, p. 47-59, 2003.

REZENDE, I. C. C.; DUARTE, J. M. S.; SILVA, P. Z. P da; SILVA, G. R. da. Análise da performance empresarial da Petrobras: um estudo sob o enfoque dos indicadores econômico-financeiros. Revista Ambiente Contábil, v. 2, n. 1, p. 54-69, 2010.

SILVA, A. S.; CORDEIRO FILHO, A. Contabilidade. Revista Brasileira de Previdência, v. 4, n. 1, p. 1-30, 2015.

SILVEIRA, A. D. M. Governança corporativa, desempenho e valor da empresa no Brasil. 2002. 165 f. Dissertação (Mestrado em Administração) - Faculdade de Economia, Administração e Contabilidade, Universidade de São Paulo, São Paulo, 2002.

Governança corporativa e estrutura de propriedade: determinantes e relação com o desempenho das empresas no Brasil. 2006. 250 f. Tese (Doutorado em Administração) Faculdade de Economia, Administração e Contabilidade, Universidade de São Paulo, 2006.

SILVEIRA, A. M.; BARROS, L. A. B. C.; FAMÁ, R. Estrutura de governança e valor das companhias abertas brasileiras. Revista de Administração de Empresas, v. 43, n. 3, p. 50-64, 2003.

SHLEIFER, A.; VISHNY, R. W. A Survey of Corporate Governance. Journal of Finance, v. 52, n. 2, p. 737-783, 1997.

UADIALE, O. M. The impact of board structure on corporate financial performance in Nigeria. International Journal of Business and Management, v. 5, n. 10, p. 155-166, 2010.

UJUNWA, A. Board characteristics and the financial performance of Nigerian quoted firms. Corporate Governance: The International Journal of Business in Society, v. 12, n. 5, p. 656-674, 2012.

WAHBA, H. The joint effect of board characteristics on financial performance: Empirical evidence from Egypt. Review of Accounting and Finance, v. 14, n. 1, p. 20-40, 2015.

Recebido em: 26-2-2021

Aprovado em: 29-7-2021

Avaliado pelo sistema double blind review.

Disponível em http://mjs.metodista.br/index.php/roc 